Review

\title{
Microreactor-Assisted Solution Deposition for Compound Semiconductor Thin Films
}

\author{
Chang-Ho Choi ${ }^{1,2}$, Brian K. Paul ${ }^{2,3}$ and Chih-Hung Chang ${ }^{1,2, *}$ \\ 1 School of Chemical, Biological and Environmental Engineering, Oregon State University, \\ Corvallis, OR 97331, USA; E-Mail: choic@engr.orst.edu \\ 2 Oregon Process Innovation Center/Microproduct Breakthrough Institute, \\ Corvallis, OR 97330, USA; E-Mail: Brian.Paul@oregonstate.edu \\ 3 School of Mechanical, Industrial and Manufacturing Engineering, Oregon State University, \\ Corvallis, OR 97331, USA
}

* Author to whom correspondence should be addressed; E-Mail: chih-hung.chang@oregonstate.edu; Tel.: +1-541-737-8548; Fax: +1-541-737-4600.

Received: 7 January 2014; in revised form: 4 May 2014 / Accepted: 6 May 2014 /

Published: 27 May 2014

\begin{abstract}
State-of-the-art techniques for the fabrication of compound semiconductors are mostly vacuum-based physical vapor or chemical vapor deposition processes. These vacuum-based techniques typically operate at high temperatures and normally require higher capital costs. Solution-based techniques offer opportunities to fabricate compound semiconductors at lower temperatures and lower capital costs. Among many solution-based deposition processes, chemical bath deposition is an attractive technique for depositing semiconductor films, owing to its low temperature, low cost and large area deposition capability. Chemical bath deposition processes are mainly performed using batch reactors, where all reactants are fed into the reactor simultaneously and products are removed after the processing is finished. Consequently, reaction selectivity is difficult, which can lead to unwanted secondary reactions. Microreactor-assisted solution deposition processes can overcome this limitation by producing short-life molecular intermediates used for heterogeneous thin film synthesis and quenching the reaction prior to homogeneous reactions. In this paper, we present progress in the synthesis and deposition of semiconductor thin films with a focus on CdS using microreactor-assisted solution deposition and provide an overview of its prospect for scale-up.
\end{abstract}


Keywords: microreactor; continuous flow; semiconductor; nanomaterial; nanostructure; thin film; solution process

\section{Introduction}

Compound semiconductors play an important role for generating, emitting and manipulating energy. State-of-the-art techniques for the fabrication of compound semiconductors are mostly vacuum-based physical vapor or chemical vapor deposition (CVD) processes. These vacuum-based techniques typically operate at high temperatures and normally require higher capital costs. Solution-based techniques offer opportunities to fabricate compound semiconductors at lower temperatures and lower capital costs. Other additional advantages of the solution-phase routes are the availability of large resources of synthetic strategies and the compatibility with soft organic materials. A variety of solution-based techniques, including electrodeposition, successive ionic-layer adsorption and reaction, spray pyrolysis and chemical bath deposition (CBD) have been developed for the fabrication of compound semiconductors [1-3]. Among these, CBD is an attractive technique owing to its low temperature, low cost and large area deposition capability [4,5]. Many semiconductor thin films have been successfully deposited using this technique, and it has already been proven to be a very useful method for fabricating large area devices, such as high efficiency $\mathrm{CuInSe} \mathrm{I}_{2}$ and CdTe solar cells. CBD processes are mainly performed using batch reactors, where all reactants are fed into the reactor and products are removed after the processing is finished. These batch processes can suffer from slow heat and mass transfer, which can result in large temperature, concentration and solution $\mathrm{pH}$ gradients. Microreactor-assisted nanomaterial deposition (MAND) processes can overcome some of the limitations of conventional batch processes and lead to large-scale manufacturing of uniform nanomaterials and nanostructured thin films [6-9]. MAND processes provide the solution-phase nanomaterial synthesis, purification, functionalization and deposition with the use of microreaction technology. The MAND process allows the control of reactants ranging from small molecules, macromolecules to nanoclusters, nanoparticles and assemblies of nanoparticles. To date, two MAND strategies have been reported: microreactor-assisted solution deposition (MASD) and microreactor-assisted nanoparticle deposition (MANpD). The MASD process is able to produce reactive fluxes of short-life, intermediate molecules for heterogeneous growth on a temperature-controlled substrate. Alternatively, the MANpD process utilizes nanoparticles or nanoparticle assemblies for the fabrication of nanostructured surfaces with various morphologies.

\section{Chemical Bath Deposition (CBD)}

Chemical bath deposition (CBD), also known as chemical solution deposition, has been known for more than a hundred years. This process can be easily implemented by immersing a substrate into a beaker, filled with an aqueous solution of chemical precursors, sitting on top of a hot plate (Figure 1a). Usually carried out as a batch process, CBD has received a great deal of attention, due to its low temperature and low cost nature. It has been used for the deposition of buffer layers in both CdTe and $\mathrm{Cu}(\mathrm{In}, \mathrm{Ga}) \mathrm{Se}_{2}$-based photovoltaics. Historically, the first application of CBD was the fabrication of 
lead sulfide photoconductive detectors in 1884 by James Emerson-Reynolds [10]. CBD is an aqueous analogue of CVD. The constituent ions are dissolved in a water solution, and the thin films are produced through a heterogeneous surface reaction. Many compound semiconductors, including II-VI, IV-VI, V-VI, and I-III-VI material systems, have been successfully fabricated by CBD processes [4].

Figure 1. (a) Scheme of a typical batch chemical bath deposition (CBD) process; and (b) photograph of a CdS-coated beaker wall.
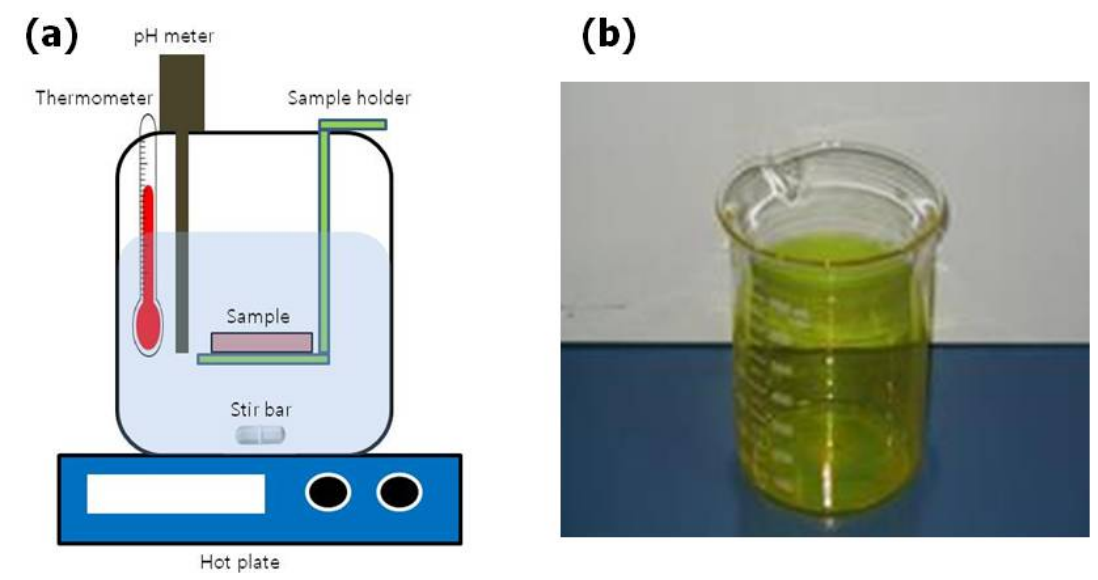

A typical growth curve of CBD measured by using quartz crystal microbalance (QCM) is shown in Figure 2 [11]. Four regimes can be identified from the QCM curve. The first one is an induction regime, where the reaction rate is slow and no clear deposition is observed. This regime corresponds to short reaction times and is marked by the beginning of nucleation. The second one is the compact layer growth regime through the molecular heterogeneous surface reactions. High quality and tightly adhering film is grown in this regime. When the growth process begins, it is characterized by a linear variation, and any minute deviation in this process can be attributed to a coalescence period. The third one is the porous layer growth regime. When the reaction time gradually increases, a clear increase in the growth rate can be observed, which corresponds to the growth of a porous layer. The appearance of this porous layer is due to the colloidal settling and sticking on the substrate created by homogeneous particle formation. However, this layer, unlike those compact layers, is weakly bonded to the substrate surface and, hence, can be removed easily, either by sonication using an ultrasonic bath or mechanical rubbing. After this, the growth rate will reach saturation and eventually stop due to the limited reagent concentration. A key issue of the batch CBD process is its difficulty in controlling the rate of the reaction once it starts. The compound is deposited from a super-saturated solution continuously everywhere in the solution, including the container wall. Figure $1 \mathrm{~b}$ shows a CdS-coated beaker after performing a CBD growth experiment. The homogeneous reaction in which nanoparticles form in the solution result in a lower yield of reactant conversion to film, which is a significant problem of the batch CBD process. The depletion of reactants from the homogeneous particle formation would also limit the achievable terminal thickness by batch CBD processes. One remedy to slow down the homogeneous precipitation in the batch CBD process is to add complexing agents or a buffer reagent, which will also slow down the surface deposition reaction. 
Figure 2. A typical growth curve and the growth mechanism of film prepared by a CBD process.

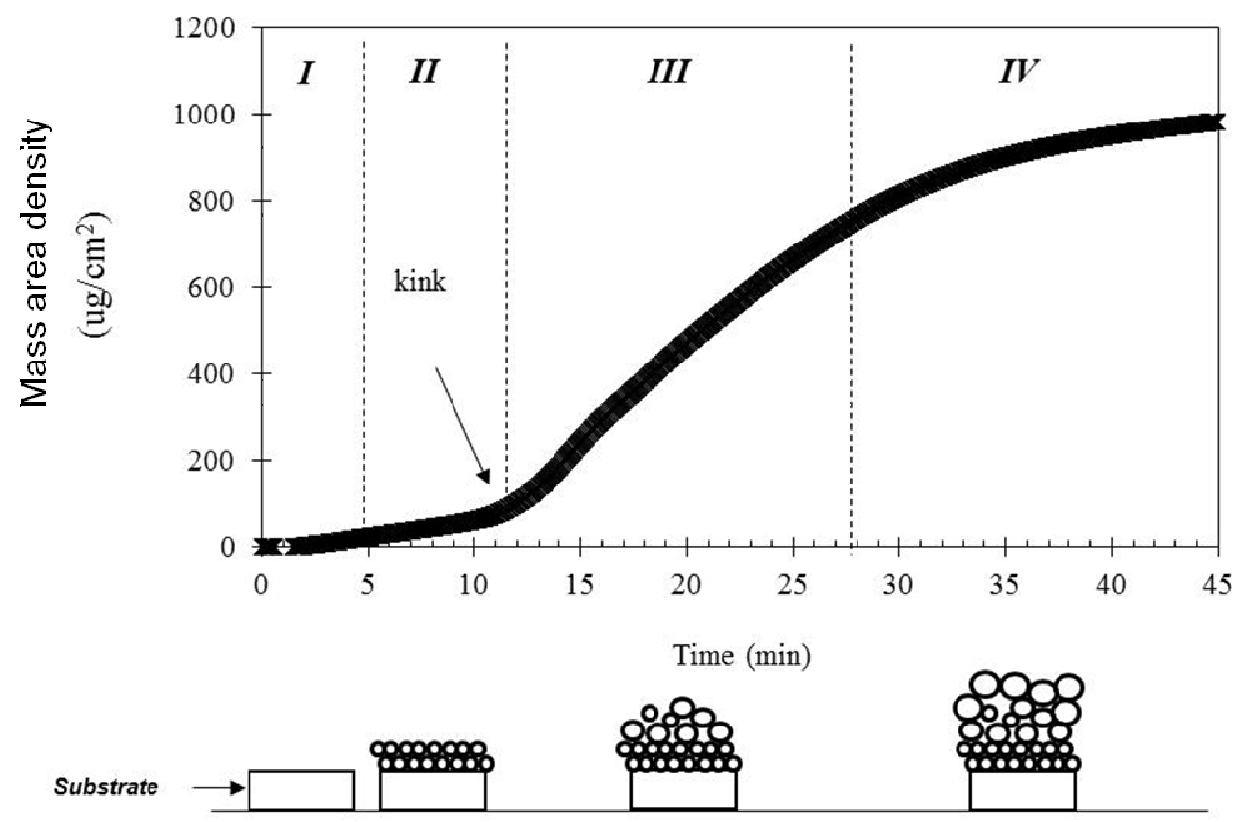

\section{Microreactor-Assisted Solution Deposition (MASD)}

MASD processes were first developed with the intent to de-couple the homogeneous particle formation and deposition from the molecular level heterogeneous surface reaction [12]. The MASD system has the capability to selectively produce intermediate, short-life molecules that are essential for the heterogeneous surface reaction on substrates, while avoiding the homogeneous particle formation reaction. This capability provides a better control of film growth and enhances the conversion of reactants into desired products (thin films). Many compound semiconductor thin films, including CdS, $\mathrm{ZnS}, \mathrm{CdTe}, \mathrm{Cu}_{\mathrm{x}} \mathrm{Se}, \mathrm{CuInS}_{2}, \mathrm{CuInSe}_{2}$ and $\mathrm{ZnO}$, have been fabricated by MASD [13-17].

The MASD process was used to fabricate the $\mathrm{CuInS}_{2}$ film on glass substrates by Park et al. [16]. Copper indium disulfide $\left(\mathrm{CuInS}_{2}\right)$ is one of the most promising ternary chalcopyrite materials, as an absorber in thin film solar cells, due to its direct band gap value (1.3-1.5 eV) [18-20]. For the deposition of the ternary $\mathrm{CuInS}_{2}$ compound, indium solution was first coated on the temperature-controlled substrate to form an indium precursor layer, and subsequently, a homogeneous mixture of copper and sulfur precursor solution from a micromixer was delivered onto the indium precursor-coated substrate. As-deposited $\mathrm{CuInS}_{2}$ film was annealed at $200{ }^{\circ} \mathrm{C}$ for $1 \mathrm{~h}$ in a vacuum furnace to generate a dense, crystalline thin film. It was found that the control of the thiourea concentration is critical in obtaining a single-phase $\mathrm{CuInS}_{2}$ film. The molar concentration of thiourea also affects the morphology of $\mathrm{CuInS}_{2}$ film. Polycrystalline $\mathrm{CuInSe}_{2}$ film was deposited using the MASD process by Kim et al. [17]. It was found that the crystallinity of the film was affected by the composition of indium. Their work demonstrated the feasibility of fabricating smooth $\mathrm{CuInSe}_{2}$ films with a large grain size, which is promising in solar cell applications.

$\mathrm{ZnO}$, a transparent, wide bandgap semiconductor material, is one of the most studied materials among various metal oxides, because of the wide variety of nanostructure shapes, easier crystal growth and earth abundance [21-23]. 
McPeak et al. implemented the chemical bath deposition using a micro-flow cell to fabricate well-aligned $\mathrm{ZnO}$ nanowire arrays [24]. They employed the spatial resolution of the microreactor to allow direct correlation of nanowire properties to process conditions. The results reveal that the lengths of nanowire decreased along the length of the flow cell, due to the depletion of precursors, morphology change from pyramidal tops to flat tops and the transition of growth mechanism from two-dimensional nuclei to spiral growth, as shown in Figure 3.

Figure 3. Cross-sectional SEM images of $\mathrm{ZnO}$ nanowires prepared at flow rates of $0.72 \mathrm{~mL} / \mathrm{h}$ (top row); and $2.88 \mathrm{~mL} / \mathrm{h}$ (bottom row) with an equimolar inlet concentration of zinc nitrate and Hexamethylenetetramine (HMT) Dimensions in each panel present the position where images were taken downstream from the inlet. The scale bar applies to all image. Reproduced from [24].
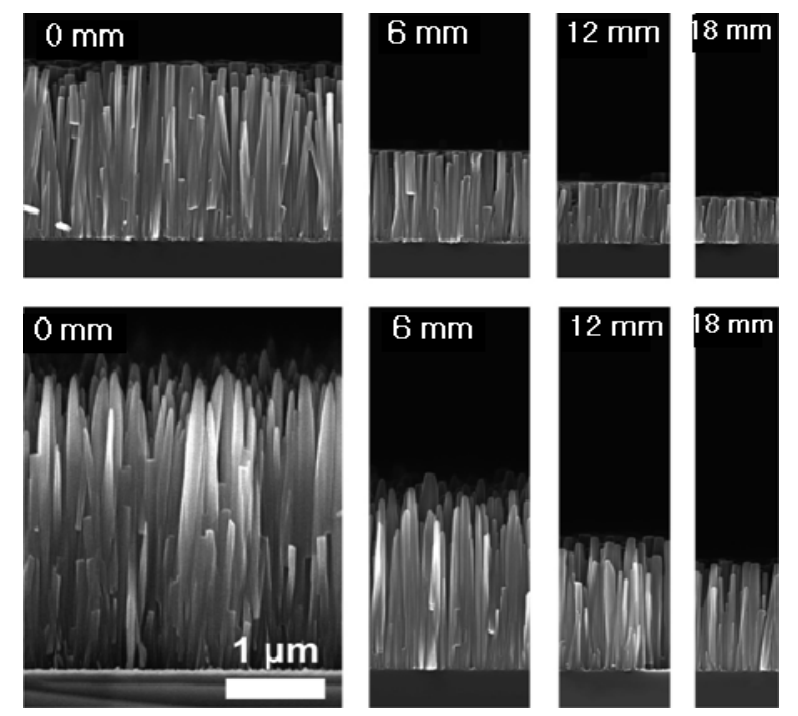

Han et al. reported the deposition of biomimetic nanostructured $\mathrm{ZnO}$ films using the MASD process, exhibiting anti-reflection on textured pyramidal silicon surfaces [25]. The pyramidal silicon substrate was prepared by a wet chemical etching process. Ag nanoparticles (Ag NPs) were separately synthesized in a solution-based process and deposited on the pyramidal silicon substrate as the seed layer for the uniform deposition of $\mathrm{ZnO}$ nanostructures. Ag NPs also provided the nucleation sites for the initial formation of $\mathrm{ZnO}$ nanostructures, leading to the well-aligned orientation of the nanostructures. $\mathrm{ZnO}$ nanorods with a length of 400 to $500 \mathrm{~nm}$ were densely grown onto the $\mathrm{Ag}$ NP-coated pyramidal silicon substrate. Dense and uniform nanostructures are attributed to the heterogeneous surface reaction that is available by controlling the residence time, reaction temperature and precursor concentration in the MASD process. The deposition rate of nanostructures was measured to be around $125 \mathrm{~nm} \cdot \mathrm{min}^{-1}$, which is highly efficient in comparison to the conventional hydrothermal reaction. The comparison of reflectance measurement reveals that the reflectance is significantly reduced as $\mathrm{ZnO}$ nanostructures are deposited onto the pyramidal silicon surface.

In the following section, investigations of $\mathrm{CdS}$ thin films prepared by the MASD system are discussed in detail to illustrate its underlying principles and benefits.

Cadmium sulfide (CdS) is an important II-VI semiconductor that is finding applications in thin film transistor, photodetector and thin film solar cells [26-28]. CdS is being used to create the $\mathrm{p} / \mathrm{n}$ junctions 
in $\mathrm{Cu}(\mathrm{In}, \mathrm{Ga}) \mathrm{Se}_{2}$ and $\mathrm{CdTe}$ thin film solar cells. Among various synthetic approaches, chemical bath deposition (CBD) is a commonly used technique for the fabrication of CdS film, due to its simple manufacturing and large area fabrication.

The MASD technique was first reported by Chang et al. to deposit CdS thin film for the fabrication of thin film transistors at low temperature $[6,12]$. The reported MASD process, illustrated in Figure 4, consisted of a micromixer, a digital pump, a heat exchanger and a hot plate. Solution 1 (a mixture of $\mathrm{CdCl}_{2}, \mathrm{NH}_{4} \mathrm{Cl}$ and $\left.\mathrm{NH}_{4} \mathrm{OH}\right)$ and Solution $2\left(\mathrm{SC}\left(\mathrm{NH}_{2}\right)_{2}\right)$ are introduced into the mixing element and countercurrently enter the interdigital channels $(30 \mu \mathrm{m})$, where they are spilt into many interpenetrated substreams. The substreams exit the interdigital channel perpendicular to the direction of the feed flows, initially with a multilayered structure. Rapid mixing through diffusion follows, due to the small thickness of the individual layer. The solution mixture of 1 and 2 pass a heat exchanger that supplies the constant reaction temperature and then are delivered onto the preheated substrate. This reactor provides the advantage of introducing constant flux of reactant solutions to the system (continuous process), which allows control over the homogeneous reaction of the chemical bath solution before the solution is delivered onto the substrate. This reactor successfully generated a reactant flux that is particle free by controlling the residence time. Using this particle-free flux, the authors were able to promote the molecule-by-molecule heterogeneous growth mechanism and prevent particle-by-particle growth [6]. Enhancement-mode CdS metal insulator semiconductor field-effect transistors (MISFETs) (Figure 5) was fabricated using this reactor at low temperature $\left(80-90{ }^{\circ} \mathrm{C}\right.$ ) without any post-deposition annealing. An effective mobility, $\mu_{\text {eff }} \approx 1.46 \mathrm{~cm}^{2} / \mathrm{V}$-sec, and a field-effect mobility, $\mu_{\mathrm{FE}} \approx 1.4 \mathrm{~cm}^{2} / \mathrm{V}$-sec, were obtained from this device [12]. Arreola-Jardon et al. reported that the as-deposited CdS-based thin film transistors fabricated from batch CBD show a field effect mobility in the range of $0.12-0.16 \mathrm{~cm}^{2} / \mathrm{V}-\mathrm{sec}$ [27].

Figure 4. Scheme of the microreactor-assisted solution deposition (MASD) technique for CdS film deposition. Reproduced from [6].

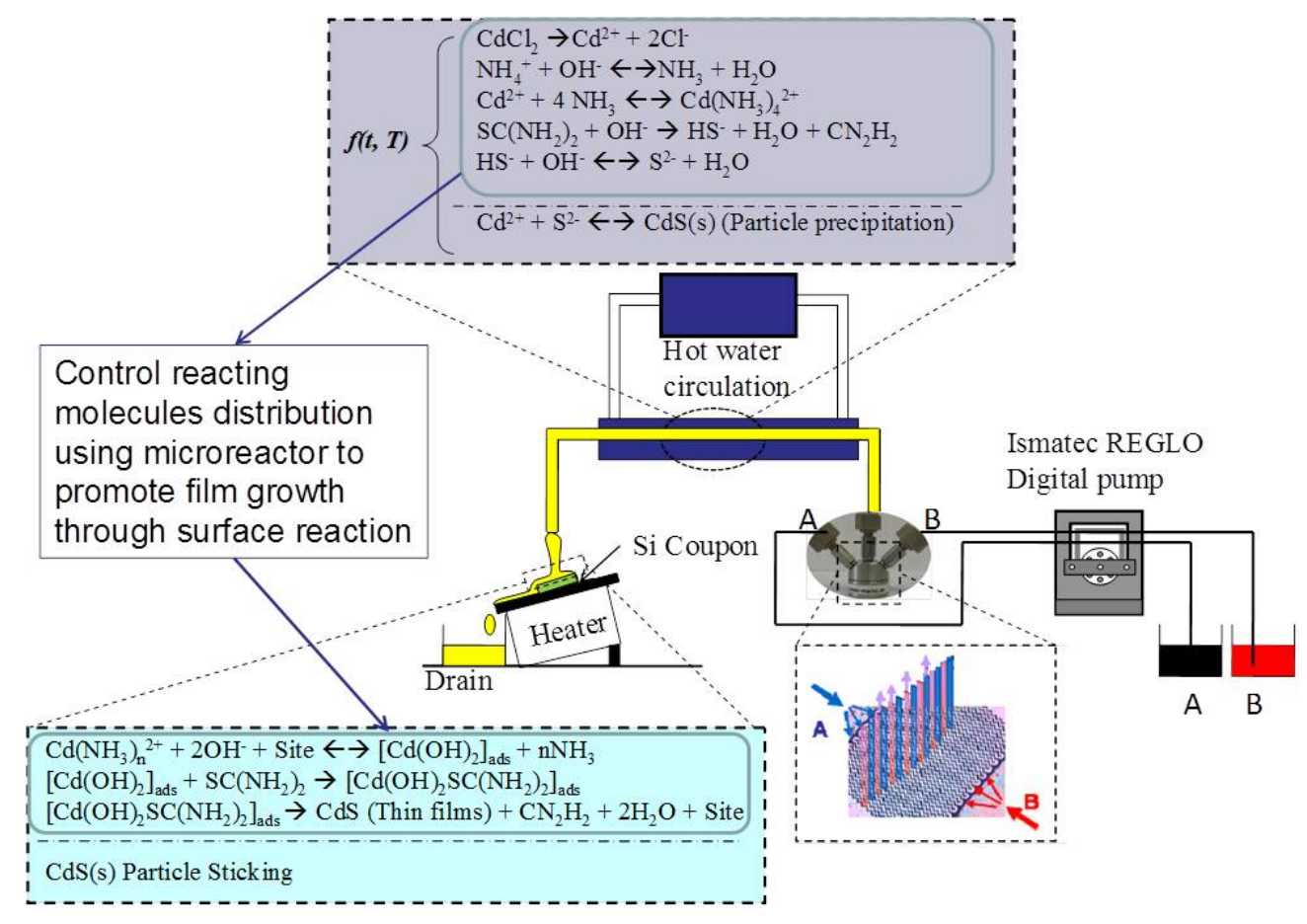


Figure 5. Structure, device performance and output characteristic curves of CdS metal insulator semiconductor field-effect transistors (MISFETs). Reproduced from [12].
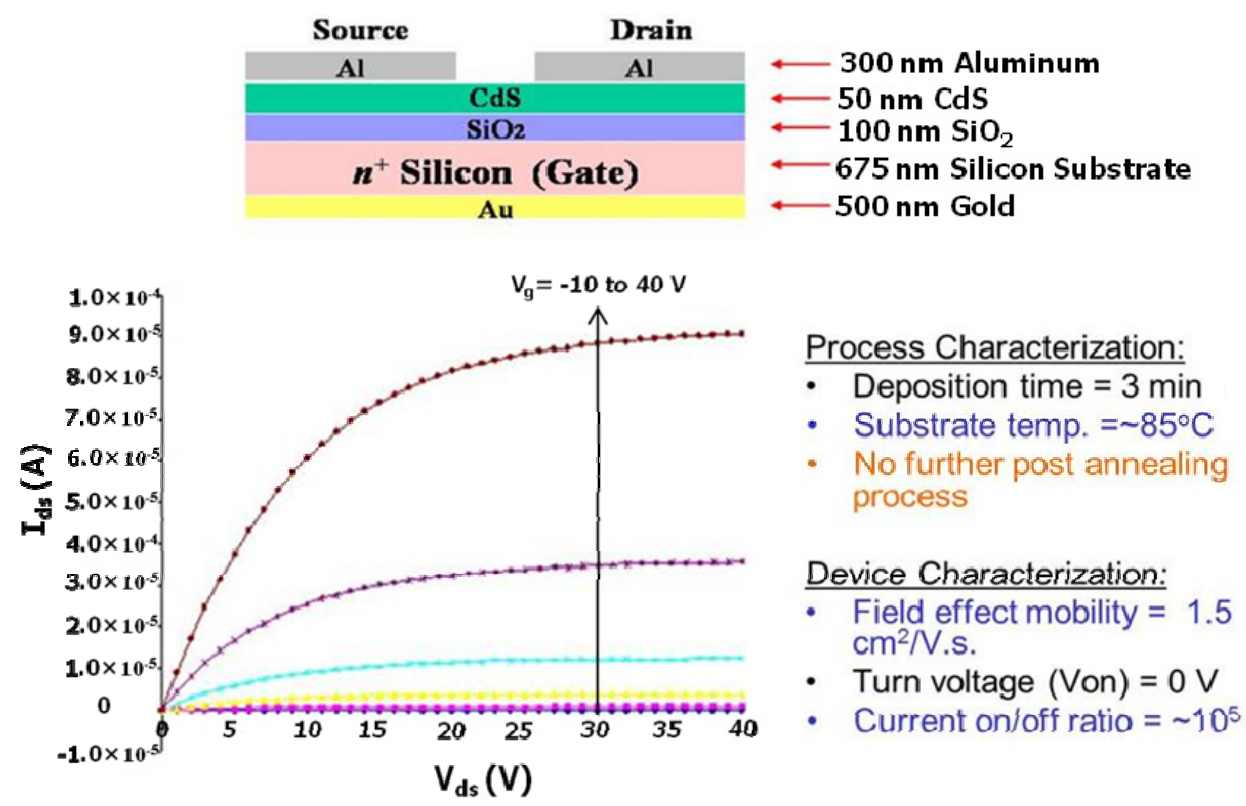

A comparison study of CdS thin film deposition by the MASD technique with the batch CBD was performed and reported by Mugdur et al. [29]. Having the same starting precursor concentration, reaction temperature and deposition time as the $\mathrm{CBD}$, the $\mathrm{CdS}$ deposition by the MASD technique was carried out. AFM analysis of CdS film prepared by the MASD technique was compared with that prepared by the CBD (Figure 6a,b). Dense and continuous film was obtained by the MASD technique, whereas discontinuous film was obtained by the CBD with the same deposition time. The RMS value of the roughness of the film by the MASD technique is $11.75 \mathrm{~nm}$ with a mean roughness of $9.61 \mathrm{~nm}$. In contrast, the RMS value of film roughness by the batch CBD technique is $19.592 \mathrm{~nm}$ with a mean roughness of $15.795 \mathrm{~nm}$. Two diffractogram peaks are shown in the XRD spectrum, corresponding to the (111) and (222) planes, respectively, from the cubic (zinc blends) phase (Figure 6c). It is indicated that the film is strongly oriented along (111) with another small peak at (222) orientation. The presence of only (111) and (222) peaks indicates the highly oriented nature of CdS films deposited by MASD, which must grow as successive alternative planes composed of only either $\mathrm{Cd}$ or $\mathrm{S}$ atoms parallel to the substrate surface, as this corresponds to the (111) planes of the cubic crystalline structure. This type of growth is in good agreement with the molecular-level growth mechanism. In contrast, Figure 6d shows a relatively broad XRD peak from the as-deposited CdS thin films by a batch CBD process that indicates its lower crystallinity. Figure 7 shows a cross-sectional SEM image of a dense CdS thin film with a thickness of around $500 \mathrm{~nm}$ deposited by MASD. The terminal thickness of the batch CBD CdS is normally limited, due to the depletion of reactants. Thus, multiple depositions are required to deposit thicker and high quality CdS films by batch CBD. Previous results indicated that for CBD CdS deposition, small particles were forming and growing even at the beginning of the deposition process, as supported by real-time dynamic light scattering measurements and TEM characterization. We have observed a similar result using MASD (Figure 8) [6]. Experiments were carried out by pre-heating the precursor solutions (stream A and B) at $80{ }^{\circ} \mathrm{C}$. At this temperature, thiourea releases more sulfide ions through hydrolysis. Free sulfide ions react with free cadmium ions 
to form CdS particles at these operation conditions. In order to obtain a solution without the homogeneous particle formation, the source chemicals have to be maintained at room temperature before they enter the micromixer. The mixed reactants are then maintained at $80{ }^{\circ} \mathrm{C}$ using heat exchanging fluid from a constant temperature circulator. TEM samples were obtained by collecting drops of hot solution from the Polyether ether ketone (PEEK) tube on the lacey carbon-coated TEM copper grid. TEM images (Figure 8d) indicate that at very short residence times (e.g., $1 \mathrm{~s}$ ), there was no evidence of particle formation on the surface of the grid under these processing conditions.

Figure 6. Comparison study of CdS film grown by the MASD with CBD: AFM image of the film by (a) the MASD and (b) the CBD, respectively; the XRD spectrum of the film by (c) the MASD and (d) the CBD, respectively. Reproduced from [29].

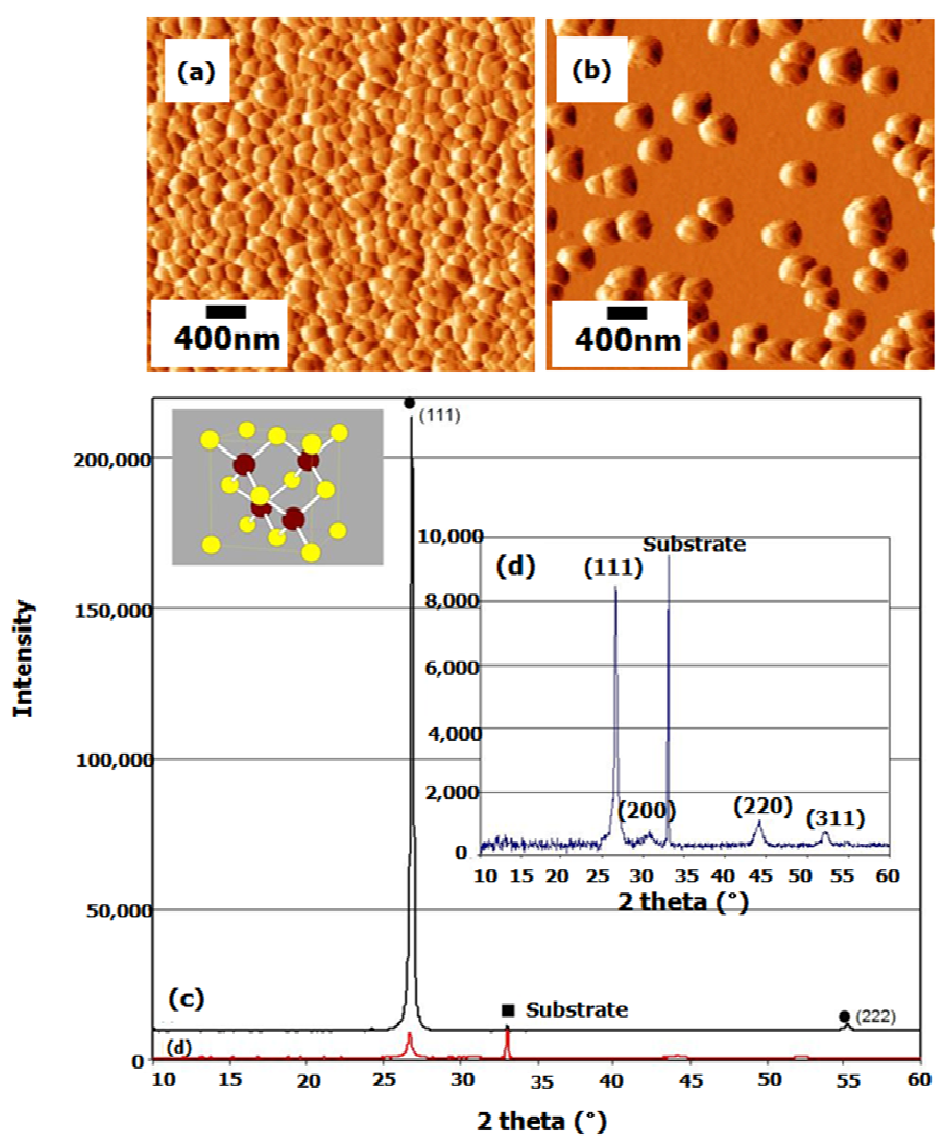

Figure 7. Cross-sectional SEM image of the CdS film grown by the MASD.

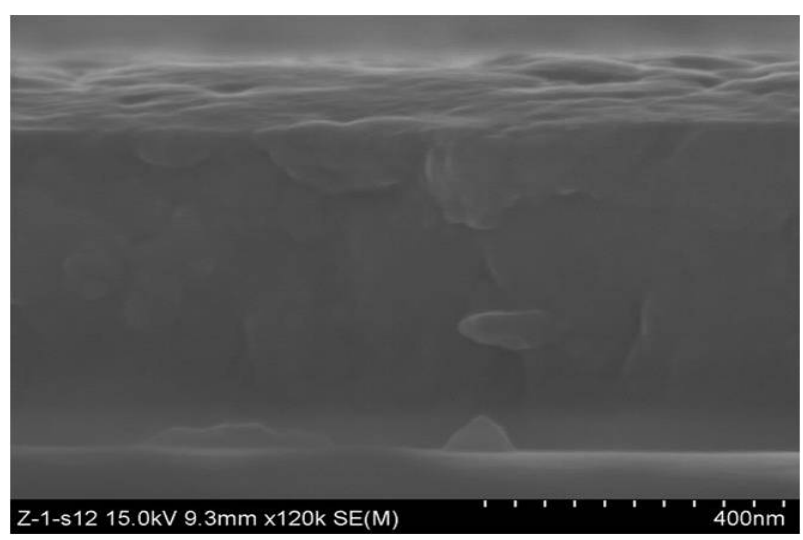


Figure 8. TEM image of $\mathrm{CdS}$ nanoparticles generated from the continuous flow microreactor with a residence time of (a) 1 , (b) 3.5 and (c) $70 \mathrm{~s}$ by preheating the precursor solutions and with a residence time of (d) $1 \mathrm{~s}$ for the precursor at room temperature. Reproduced from [6].
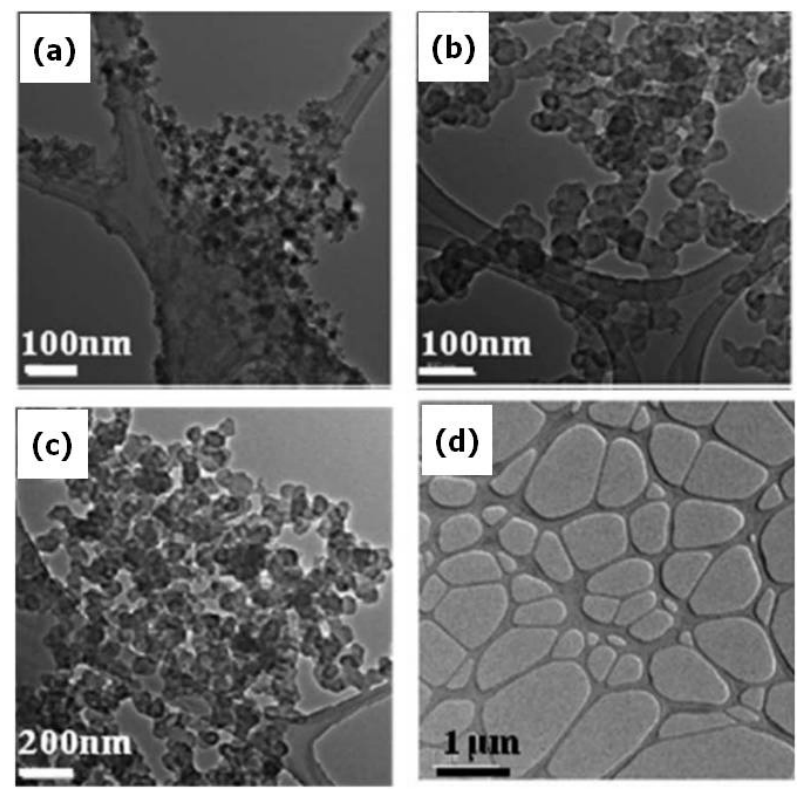

Using a particle-free flux study of the CdS deposition kinetics via the heterogeneous surface reaction by a molecule-by-molecule growth mechanism could be realized. A series of CdS thin film deposition experiments at different residence times (1, 3.5, 7, 35 and $70 \mathrm{~s})$ were performed. The film thickness was determined by a surface profiler (Veeco, Plainview, NY, USA, 3D Dektak 8). Figure 9a shows the deposited $\mathrm{CdS}$ thin film thickness versus the deposition time at different residence times. The fitted linear regression lines were also plotted to obtain growth rate values. These growth rate results in Figure 9b clearly indicate that a lower CdS thin film growth rate was obtained ( $77 \AA$ Á/min) when a 1-s residence time was used. The growth rate increases significantly (about four times higher) when a 3.5-s residence time was used compared to a 1-s time. The thin film growth rate increases gradually from a 3.5-s to a 35-s residence time. However, when a 70-s residence time was used, the growth rate decreased. These results clearly demonstrate the capability of MASD to control the reaction kinetics of chemical solution deposition beyond the batch process. In addition, these results also demonstrate the utility of MASD as a valuable tool to investigate the chemical solution deposition processes. The pioneering studies by Ortega-Borges and Lincot and Doña and Herrero suggest that thiourea reacts with either cadmium hydroxide or dihydroxo-diammino-cadmium complex to form different adsorbed metastable complexes for CBD CdS deposition [5,30]. The proposed molecular-level heterogeneous reaction mechanism is given in Equations (1) to (3).

$$
\begin{aligned}
& \mathrm{Cd}\left(\mathrm{NH}_{3}\right)_{4}^{2+}+2 \mathrm{OH}^{-}+\text {site } \underset{\mathrm{k}_{-1}}{\stackrel{\mathrm{k}_{1}}{\rightleftarrows}} \mathrm{Cd}(\mathrm{OH})_{2 \text { ads }}+4 \mathrm{NH}_{3} \\
& \mathrm{Cd}(\mathrm{OH})_{2 \text { ads }}+\mathrm{SC}\left(\mathrm{NH}_{2}\right)_{2} \stackrel{\mathrm{k}_{2}}{\longrightarrow}\left\{\mathrm{Cd}\left[\mathrm{SC}\left(\mathrm{NH}_{2}\right)_{2}\right](\mathrm{OH})_{2}\right\}_{\text {ads }} \\
& \left\{\mathrm{Cd}\left[\mathrm{SC}\left(\mathrm{NH}_{2}\right)_{2}\right](\mathrm{OH})_{2}\right\}_{\text {ads }} \stackrel{\mathrm{k}_{3}}{\longrightarrow} \mathrm{CdS}+\mathrm{CN}_{2} \mathrm{H}_{2}+2 \mathrm{H}_{2} \mathrm{O}+\text { site }
\end{aligned}
$$


The CdS growth rates should be proportional to the concentration of thiourea, according to this reaction mechanism. The initial thiourea concentrations are the same for all of the MASD experiments. The thiourea concentration should decrease as a function of residence time, due to the hydrolysis Reaction 4:

$$
\mathrm{SC}\left(\mathrm{NH}_{2}\right)_{2}+\mathrm{OH}^{-} \longrightarrow \mathrm{HS}^{-1}+\mathrm{CN}_{2} \mathrm{H}_{2}+2 \mathrm{H}_{2} \mathrm{O}
$$

One would expect a slight reduction of the deposition rate at a longer residence time. The observed results suggest that the dominant reacting sulfur molecule that is responsible for CdS thin film deposition is not thiourea, but $\mathrm{HS}^{-}$. At the short residence time of $1 \mathrm{~s}$, the concentration of sulfide ions formed through the thiourea hydrolysis reactions and is lower than the concentration of sulfide ions at a longer residence time, thus resulting in a lower growth rate of CdS thin film. Between 35 and $70 \mathrm{~s}$ of residence time, nanoparticles start to form in the solution and to reduce the reacting molecular species. The proposed reaction mechanism is illustrated in Figure 10 [31].

Figure 9. Fabrication of CdS thin film using MASD process: (a) CdS thin film thickness versus deposition time and (b) growth rate as a function of different residence times. Reproduced from [6].
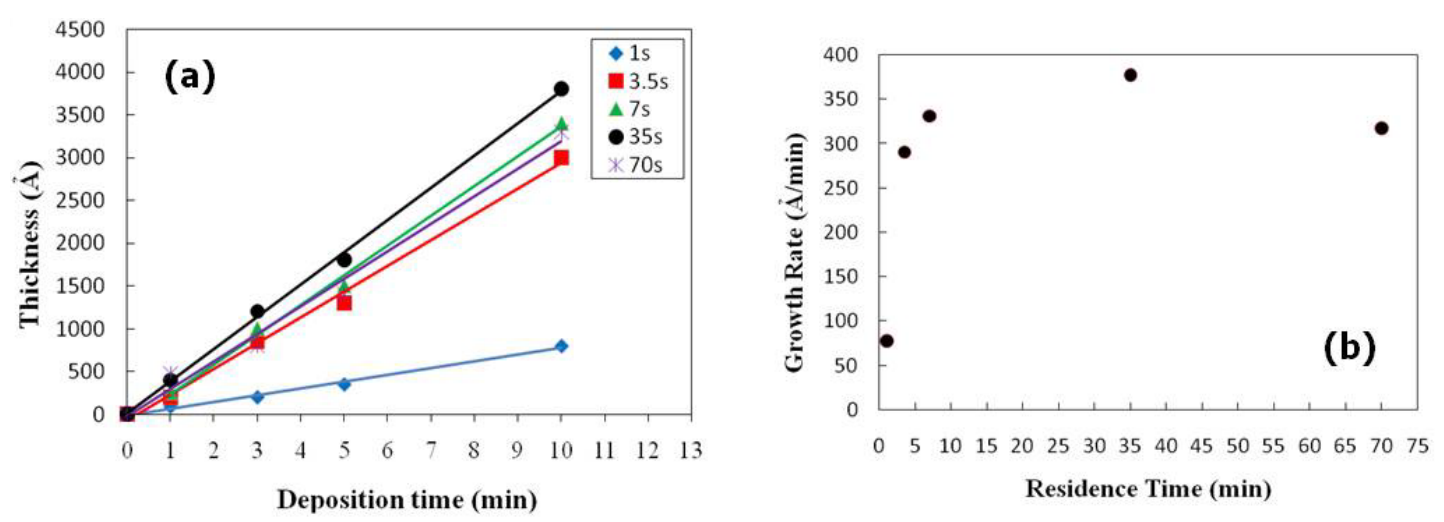

Figure 10. Growth mechanism of $\mathrm{CdS}$ thin film in the batch $\mathrm{CBD}$ process.

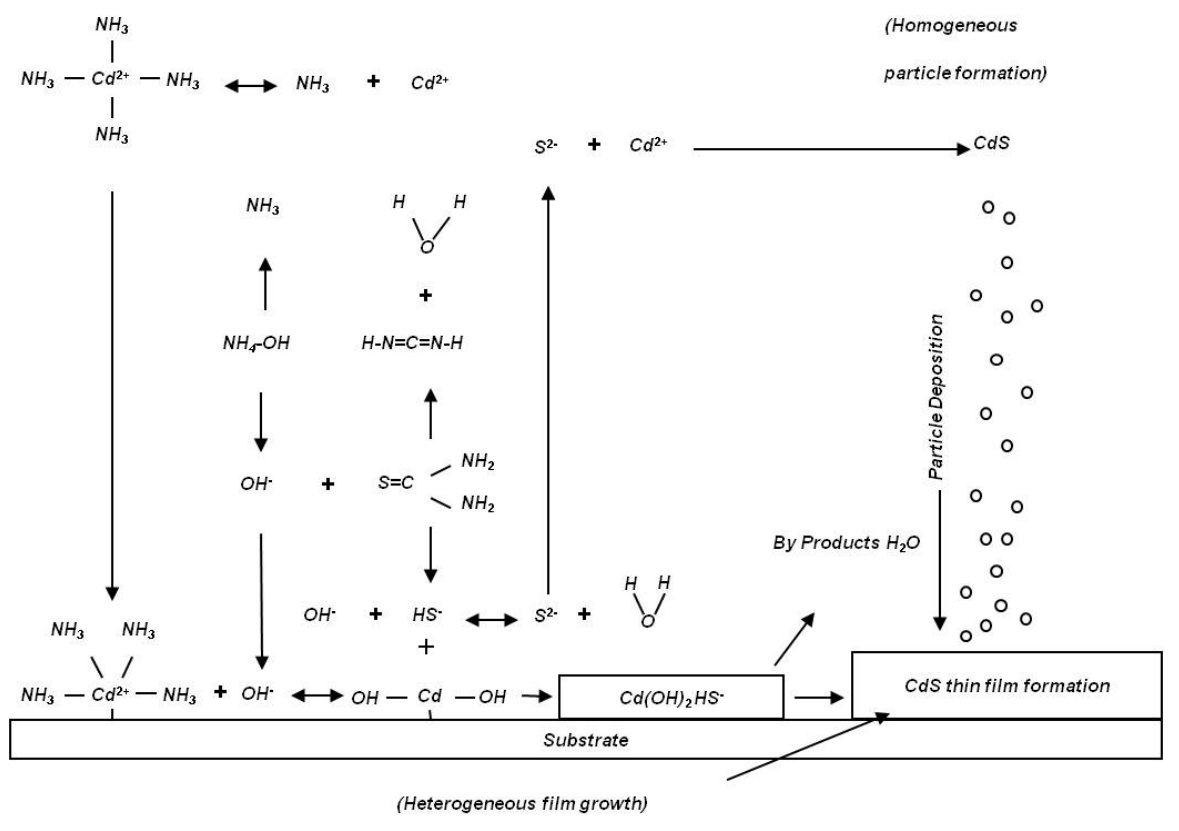


In a conventional batch CBD process, the heat needed for chemical reaction is supplied from the solution bath to the sample surface, resulting in both heterogeneous CdS nucleation at the surface, as well as homogeneous CdS formation in the bath. Hence, for baths involving a thermal jacket (glass beaker, etc.) or water bath, significant $\mathrm{CdS}$ deposition also occurs on the walls of the vessels. A significant amount of chemical precursors were converted into the formation of $\mathrm{CdS}$ particles in the solution. Normally, the bath was stirred continuously to ensure uniform thermal and chemical mixing and to minimize the sticking of CdS particles to the growing film surface. Moreover, the unequal volumes of the bath used to form the desired CdS film generates a lot of waste and creates defects in devices. Several groups of researchers have found ways to increase the precursor conversion yield [32]. Boyle et al. reported a modified CBD process that incorporate a filtration unit with the potential for continuous reaction by replenishment, treatment and purification of reagents within a recirculating closed-loop CBD reactor [33]. Nair et al. reported a technique to improve thin-film yield in the chemical bath deposition of semiconductor thin films [32]. The concept is to use a very small substrate separation, $0.1 \mathrm{~mm}$, to eliminate the passive layer of the bath, which contributes solely to precipitation. In small substrate separation, a thin layer of the bath mixture is held by surface tension between pairs of substrates. The thin-film yield obtained in their work approaches $100 \%$ for $\mathrm{CuS}$, $\mathrm{Cu}_{2-x} \mathrm{Se}, \mathrm{CdS}$ and $\mathrm{CdSe}$ thin films. The final thickness estimated for the films is about 40-50 nm after a deposition time of 6 to $16 \mathrm{~h}$. The combination of MASD with these innovative approaches should result in achieving an optimum film quality, growth rate and precursor by controlling the reacting chemical flux, the bath-to-surface volume and reaction temperatures.

\section{Scale-Up of MASD Processes}

To achieve reasonable volumetric flows, microchannel components are scaled-up by numbering-up i.e., scaling-up by repeating microchannel unit operations in parallel to increase the cross-section of flow [34,35]. Numbering-up may be accomplished either internally or externally [36]. Internal numbering-up involves arraying an original microchannel as an array of parallel microchannels within a single reactor component. An internal flow distribution system must be designed and implemented as part of the component to ensure equivalent reaction conditions in each channel. However, when scaling-up a process, the size of a single reactor component can be limited by either the size of the raw material available or the size of the work envelope for the fabrication processes used to produce the component [35]. Consequently, external numbering-up can be used to scale-up the process further by putting a number of reactor components in parallel, allowing the original flow to be split evenly between the components. External numbering-up has the advantage that clogged components can be replaced without throwing away the remaining reaction capacity. However, external numbering-up can suffer from poor flow distribution between components and is logistically more difficult and expensive to implement.

Theoretically, the scale-up of microreactors is made easier by maintaining equivalent thermal, chemical and temporal reaction conditions within an array of microchannel unit operations. However, maintaining equivalent reaction conditions through channels of varying sizes and between components having different dimensions can be difficult, due to the effect on flow conditions. Saber et al. investigated the effects of flow maldistribution on microreactor performance and found that for mass 
transfer-limited reactions, flow maldistribution had a more pronounced negative effect on reaction selectivity than for kinetic-limited reactions [37]. Further, the researchers distinguished flow maldistribution due to poor manifolding during external numbering-up from that due to internal clogging. Internal clogging was found to have little effect on flow distribution, yet a relatively larger effect on the sensitivity of the reaction selectivity, due to reasons other than hydrodynamic effects. Tonomura et al. performed numerical and experimental studies showing that pressure drop control is superior to total flow control for managing internal blockage between externally numbered-up components [38]. The team validated these findings by implementing pressure drop control across four parallelized microchannel heat exchangers.

However, external numbering-up can be expensive, due to the amount of process control equipment required for each added device. Efforts have been made to simplify external numbering-up through the use of flow splitters that efficiently distribute a single flow into several uniform subflows, reducing the number of pumps [36,39]. Kashid et al. demonstrated the external numbering-up of a two-phase capillary reactor using two six-channel polytetrafluoroethylene (PTFE) flow distributors (one for gas and one for liquid), six Y-shaped mixing elements and six glass capillaries [40]. Though no reactions were conducted, the mass transfer characteristics for the six channel unit were found to track with those of a single capillary.

The technical literature provides various demonstrations for scaling the production of various chemistries using microchannel reactor technology. Iwasaki et al. demonstrated six days of operation of a microchemical pilot plant consisting of a static T-micromixer followed by eight microtube reactors in a tube-and-shell arrangement for the numbering-up of a radical polymerization reaction [41]. Results showed that at eight-fold the flow rate, a similar yield, molecular weight and molecular weight distribution were produced in the numbered-up reactor compared to the single microtube reactor. Deshmukh et al. demonstrated the ability to scale-up the Fischer-Tropsch synthesis of synthetic fuels from a single microchannel to 276 parallel process microchannels at a production rate of 1.5 gallons per day [42]. The process was found to provide equivalent outcomes, including syngas conversion and selectivity to a byproduct, across three orders of magnitude. Mae et al. (2004) introduced two types of splitting and recombination micromixers that enabled the rapid aqueous extraction of phenol from dodecane within one second under a flow rate of 5-20 liters per hour [43]. Kockmann et al. demonstrated the numbering-up of a two-step organo-metallic reaction operated at two temperature levels [44]. The final reactor contained $1 \mathrm{~mm}$ in diameter mixing channels and supported overall production rates of 700 grams per minute, leading to the production of more than two tons of isolated material. Bally et al. discussed the design of a 2000 metric tons per year pilot plant with 28 interdigitated micromixers to mix the inlet flow of four tubular reactors to avoid precipitation in homogeneous polymerization reactions, which formed the basis of a patent $[45,46]$. Many additional examples of microreactor pilot plants for organic syntheses are provided by Wirth [47]. Fox et al. describe a numbered-up pulsed electric field reactor design for use in pasteurization [48].

CBD is relatively easy to scale-up across large surfaces. However, as a batch process, CBD can offer low material utilization for chemistries involving competing reactions. MASD techniques are capable of providing the reaction selectivity and a short-life, intermediate chemistry unattainable in CBD. Other benefits include reduced energy requirements and processing times for long synthesis reactions and characteristically small reaction volumes, which can reduce human exposure to 
hazardous chemistries. The benefits of using microchannel reactors are primarily realized in diffusion-limited processes. An estimate for the mean time needed for molecules to diffuse in mass transfer is to the square of the channel radius over the diffusivity coefficient of the chemistry. Therefore, a tenfold reduction in tube diameter results in a one hundred-fold reduction in the residence time. The accelerated heat and mass transfer provides better process control, while reducing the size and weight of reactors. For diffusion-limited reactions, the use of microchannel components reduces the size and weight of the reactor apparatus, making implementation of MASD easier. Through the use of microchannel reactor components, temporal control of the chemistry enables the reactant stream to be introduced to the reaction surface at the peak of its reaction potential. Conceptually, a continuous flow MASD reactor for producing thin films from reactive chemistry will include a micromixer, a heat exchanger, a residence time unit and a flow cell for controlling deposition onto a substrate (see Figure 11). A scale-up study of MASD using a flow cell was reported by Paul et al. $[9,49,50]$.

Figure 11. A typical MASD setup. Reproduced from [49].

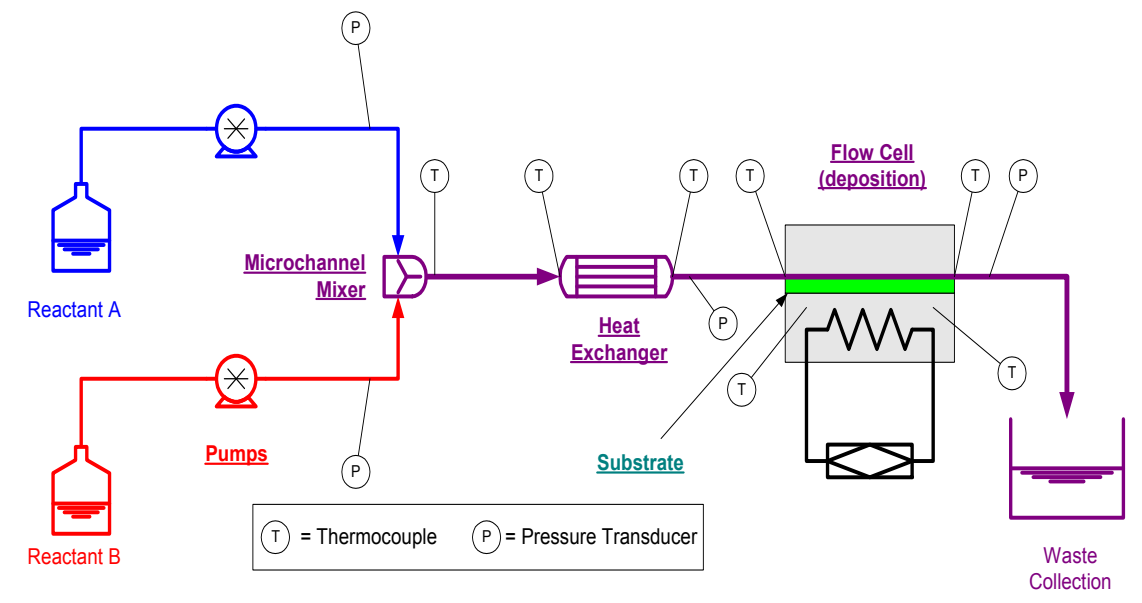

While the numbering-up of pilot plants have been demonstrated for many chemistries, a key to enabling MASD is the use of small, lightweight reactors capable of providing the distributed production of solution chemistries. The size and weight of microchannel reactors was envisioned early in the development of microreactor technology for enabling the distributed production of chemical products [51]. A key component of MASD is a micromixer. Micromixers offer features that cannot be easily achieved by macroscopic devices, such as ultrafast mixing on the microscale. For example, Bökenkamp et al. fabricated a micromixer as a quench-flow reactor to study fast reactions (millisecond time resolution) [52]. A variety of micromixers have been reported in the literature, including static and dynamic mixers [53,54]. A simple T-mixer was used in the 6" MASD system reported by Paul et al. [48]. T-mixers are relatively cheap and simple to fabricate; however, they might face a limitation to further scaling up. Other micromixers, such as oscillatory flow mixers and interdigital micromixers, could be used for the higher flow requirement. Oscillatory flow mixers fall into two categories. Pressure-driven oscillatory mixers have been shown to be capable of sustaining the largest production rates of nanoparticle chemistries reported to date, while piezo-driven ones, being compact and precise, have not been shown to provide adequate production rates [55,56]. Interdigital micromixers seem to provide the smallest format at a reasonable production volume. In the case of numbering-up the synthesis of phosphine-stabilized undecagold nanoclusters, Jin et al. used an 
interdigital micromixer to demonstrate a production rate 500 times greater and a yield over 3.5 times higher than that of a conventional batch process [57]. To demonstrate the ability to internally number-up the reaction, the number of plates in the mixer was doubled (double the flow cross-section) and the overall flow rate was quintupled, leading to a five-fold increase in the production rate to $7.1 \mathrm{~kg}$ per week, while maintaining a constant material conversion rate. The largest micromixer used was just under $1.7 \mathrm{~cm}^{3}$ in volume.

Ramprasad et al. developed an adjustable residence time heat exchanger, suitable for MASD, comprised of two sections integrated in a single device; a rapid heating zone (HZ) and an adjustable residence time (RT) section, as shown in Figure 12 [9]. The heat exchanger is a composite unit consisting of copper plates at the top and bottom, to seal the polycarbonate channels, which are interposed between silicone gaskets. Copper was chosen because of its high thermal conductivity. An ESI (Portland, OR, USA) Laser 5330 was used for machining of the micro-channels in polycarbonate and silicone. This entire unit was bolted together to provide a leak-proof system. The HZ is the initial section of the polycarbonate channel in which the mixed reagents enter at room temperature and are heated to the set-point temperature in roughly one second. The hot fluid exiting from the heating zone enters the RT unit of the heat exchanger. The function of the RT unit is to maintain the fluid at the HZ exit temperature, while providing the specific additional residence time of the hot fluid before deposition onto the substrate (Figure 13). The residence time in the heat exchanger is contingent on the number of polycarbonate plates in the heat exchanger assembly. The heat exchanger is designed such that the first polycarbonate plate is an integrated device consisting of both the HZ and the RT unit. This integrated unit of the HZ and RT polycarbonate plate is sandwiched between two silicone gaskets. However, the option of exclusively augmenting only the polycarbonate RT plates may be utilized to achieve the desired higher residence time. The schematic of the residence time configuration is shown in Figure 11. Two silicone strip heaters are overlaid onto the RT units both on the top and bottom to provide sufficient heat to maintain the fluid at the desired temperature. A total of four ceramic heaters were used, with two heaters on each face of the HZ section.

Figure 12. A schematic representation of residence time configurations available in the adjustable residence time heat exchanger (a) $1 \times$; (b) $5 \times$; (c) 10×. Reproduced from [9].

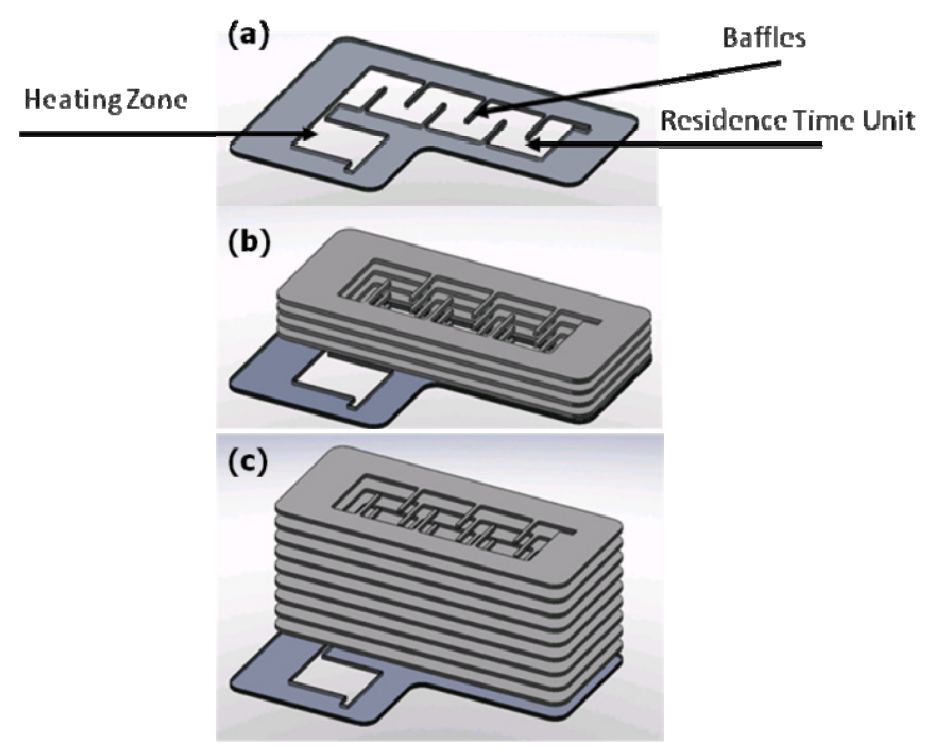


Figure 13. The temperature variation as a function of the residence time in a comparison of a micro-channel heat exchanger with conventional chemical bath deposition. Reproduced from [9].

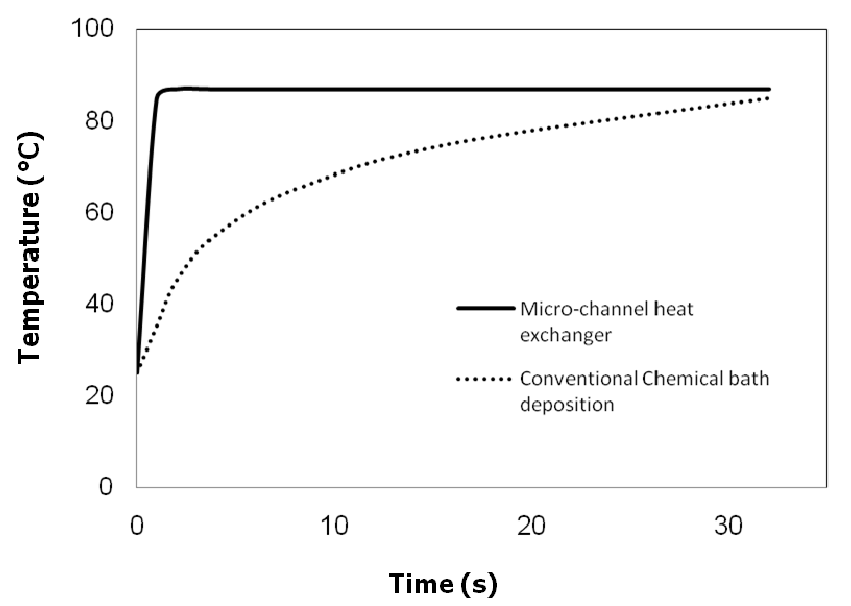

A key challenge for scaling up MASD is the requirement for film uniformity over large substrates, which requires that reaction conditions are uniform over the target substrate. Surface reaction kinetics are highly dependent on the reactant concentration and temperature at the reactive surface. In the case of reactants supplied as a continuously flowing fluid, the velocity at which the fluid travels determines the residence time over which the reactants have access to the deposition surface. For large substrates $150 \mathrm{~mm}$-wide or more, it can be difficult to maintain constant fluid residence time across the entire surface. Further, faster flowing fluid results in a thinner boundary layer through which reactants diffuse. This difference in residence time and boundary layer thickness produces a variable film thickness, which is undesirable for the final cell functionality.

In a pressure gradient-driven system, a challenge arises when transforming a virtual "point source" fluid supply from tubing to a uniform velocity front across a comparatively large surface area and then back to tubing for collection. In this chapter, the function of a flow cell is to manage flow distribution across the thin film substrate. Little has been published regarding flow cell designs used in scaling up liquid-phase continuous flow deposition.

The basic flow cell design consists of a fluid cavity between two parallel plates with an inlet and an outlet. Efforts have been made in adjacent fields to manage flow distribution within various types of flow cell arrangements. Chung et al. presented a flow cell design for cell culture cultivation having over-sized inlet and outlet reservoirs designed as long plenums, as shown in Figure 14 [58]. The long plenums have a low pressure drop, which helps to distribute the fluid laterally prior to flowing over the parallel plate region, effectively managing the lateral variation of fluid velocity.

In a similar manner, PDMS flow cells were developed by Hung et al. to provide nutrients to a cell culture system in a uniform and controlled manner [59]. An outer plenum was connected to the flow cell using small perfusion channels, which have greatly reduced cross-sectional areas and much larger pressure drops than the plenum (Figure 15). The size of the perfusion channels can be used to effectively manage the fluid velocity across the flow cell (Figure 16). 
Figure 14. Schematic of flow chamber with inlet/outlet reservoirs. Reproduced from [58].

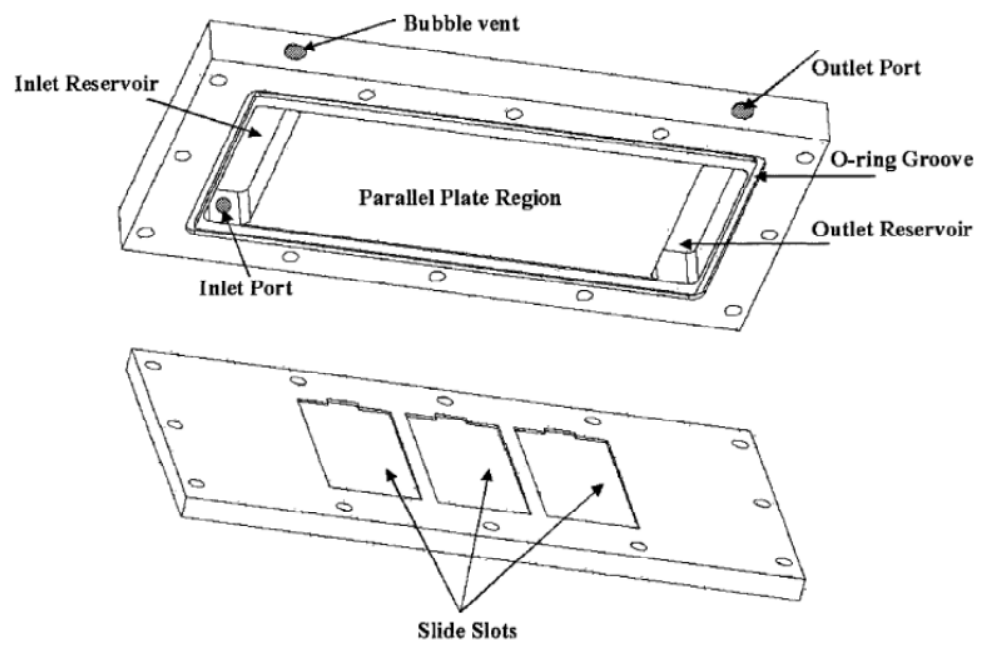

Figure 15. (a) Magnified view of the cell chamber; (b) magnified view of the perfusion channels. Reproduced from [59].
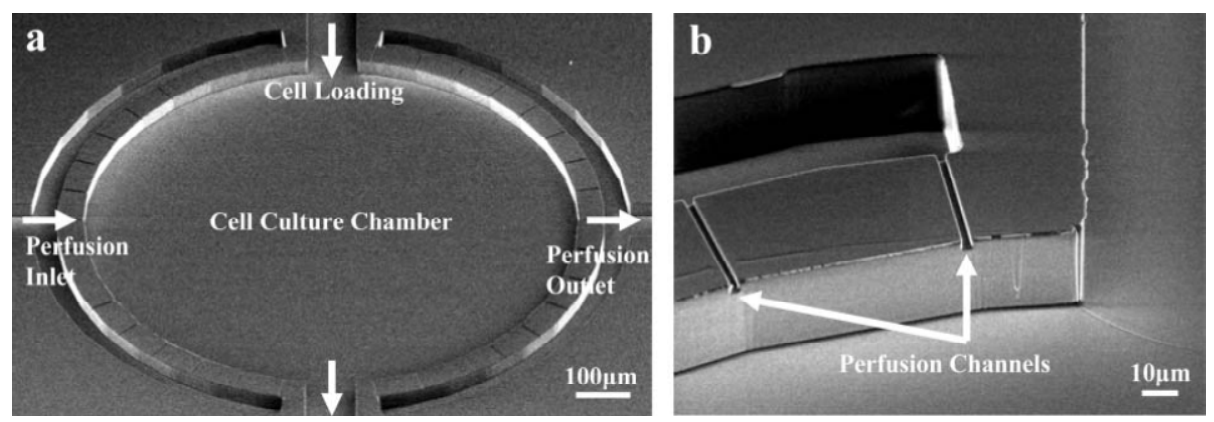

Figure 16. (a) Time-stepped computational fluid dynamics (CFD) simulation of fluid velocity; (b) time-stepped colored dye observation. Reproduced from [59].
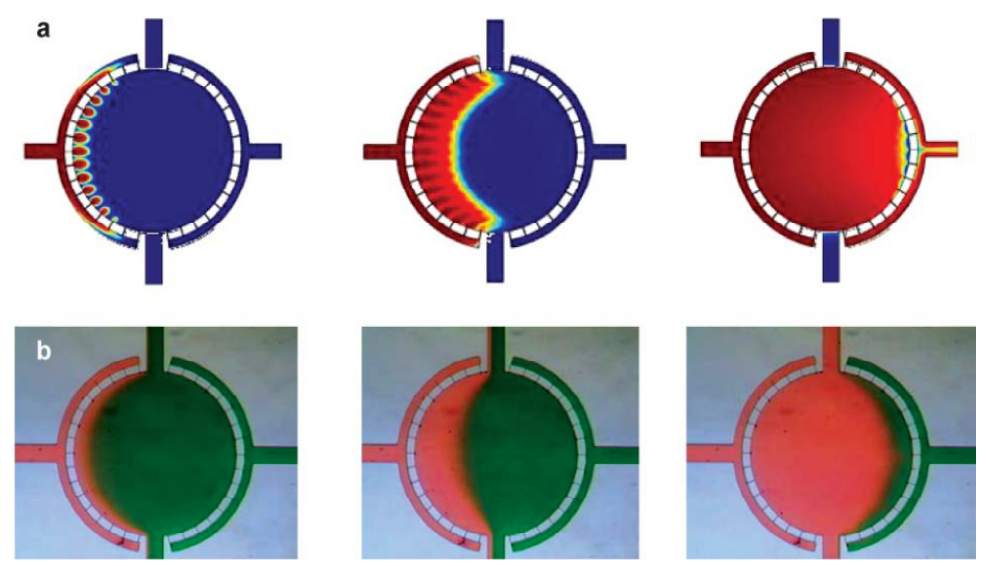

However, fluid flow analysis of these types of flow cells shows that the large plenums contain "dead" zones, where fluid stagnates, causing a larger residence time distribution within the flow cell. For systems containing reactive species, precipitates may form in dead zones, which inherently reduces the material utilization and can lead to clogging, which would alter the flow field across the flow cell.

Jones et al. investigated the flow distribution effects of the flow geometry in the plane parallel to the fluid plane of a microchannel heat sink [60]. Figure 17 depicts the change in the velocity profile 
between two flow geometries; one with a constricted geometry around the inlet and outlet versus a design with unconstrained flow from the inlet and outlet. Experimental analysis showed a much better flow distribution in the case of the unconstrained flow with a $4.7 \%$ difference between the maximum and minimum mass flux across the channel array for the unconstrained design versus a $33.5 \%$ difference for the constrained design. The unconstrained design also realized a significantly lower pressure drop.

Figure 17. Velocity contours of circular top down inlets. (a) Constrained design around the inlet/outlet; (b) Unconstrained design. Reproduced from [60].

a
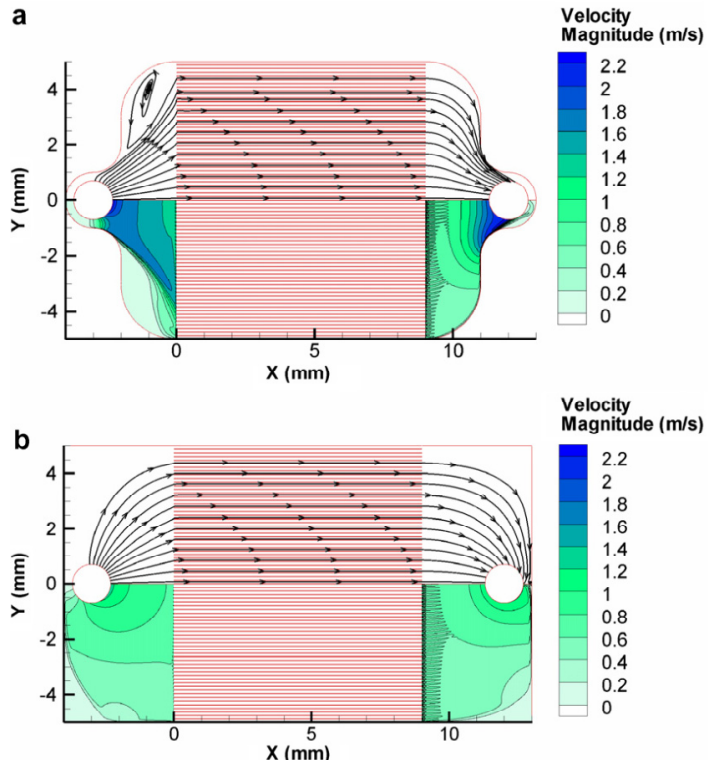

b

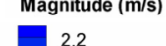

Pan et al. characterized a microscale flow chamber composed of several parallel rectangular channels and used an electrical network parody to describe the system (Figure 18) [61].

Figure 18. Microdevice design and analytical model. Reproduced from [61].

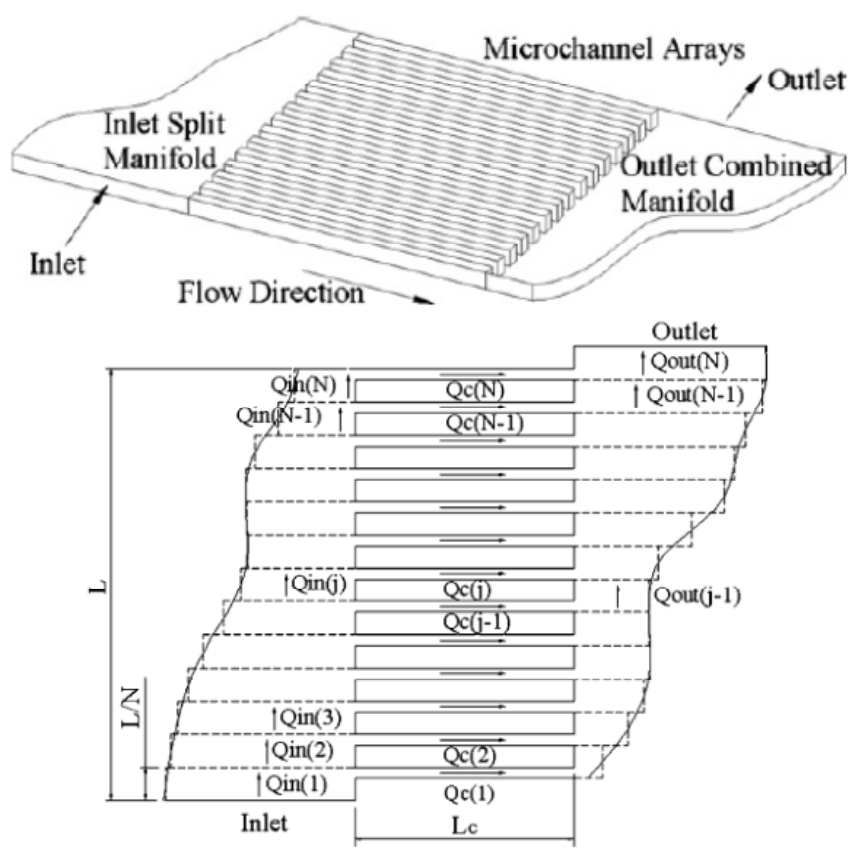


Operating under laminar flow conditions, the pressure drop of each channel using the Hagen-Poiseuille equation for rectangular channels is:

$$
\Delta P=\frac{32 \mu L \lambda_{\mathrm{NC}}}{D_{\mathrm{H}}^{2}} U=\frac{32 \mu L \lambda_{\mathrm{NC}}}{D_{\mathrm{H}}^{2} A} Q
$$

where $A$ is the channel cross-sectional area, $L$ is the channel length, $U$ is the velocity, $D_{H}$ is the hydraulic diameter, $D_{H}=2 H W /(H+W)$; and $\lambda_{\mathrm{NC}}$ is a non-circular correction coefficient of $(3 / 2) /\left((1-0.351(E / W))^{2}(1+H / W)^{2}\right)$ for $W>H$. In the model, the "loop rule" of $V=I R$ used for electrical circuits was made analogous to the Hagen-Poiseuille equation for fluidic circuits by replacing the voltage, current and electrical resistance with pressure drop, volumetric flow rate and the following term for flow resistance:

$$
R=\frac{32 \mu L \lambda_{\mathrm{NC}}}{D_{\mathrm{H}}^{2} A}
$$

The basic overall resistance model assumes each channel is associated with its own unique inlet $\left(R_{\text {in }}\right)$ and outlet $\left(R_{\text {out }}\right)$ region, resulting in a unique potential difference $(\Delta P)$ across each channel. This leads to a system of flow resistances in both series and in parallel, as shown in Figure 19. Varying the length, depth and number of channels allowed the optimization of the inlet and outlet geometries for uniform a flow distribution between each channel.

Figure 19. Microdevice design and the equivalent electrical resistance model. Reproduced from [61].

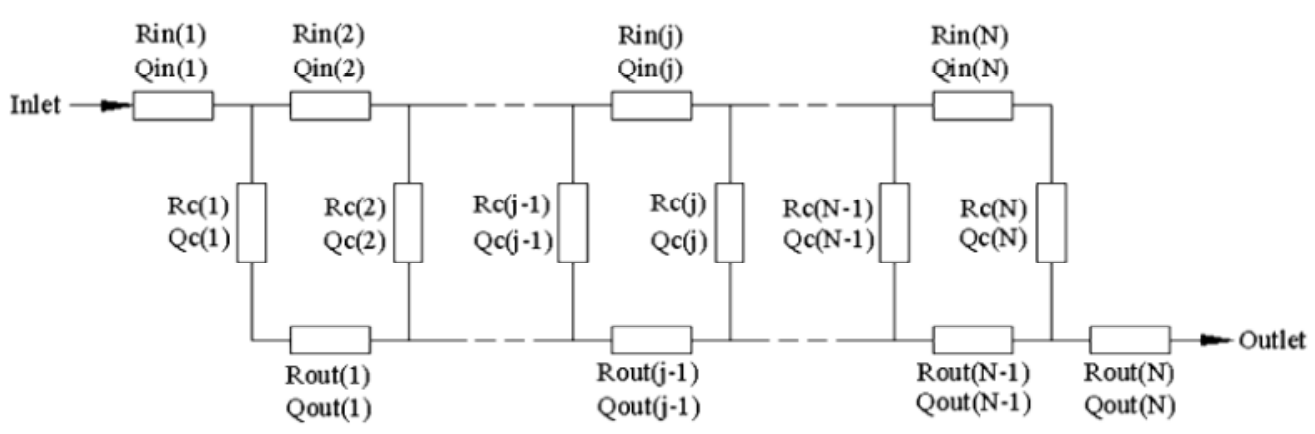

Paul et al. developed a MASD flow cell with a more uniform fluid residence time for depositing CdS buffer layers for thin film photovoltaics over a $150 \mathrm{~mm}$-sized glass substrate coated with fluorine-doped tin oxide (Figure 20) [49]. The geometry of the flow cell in the flow plane reflects efforts to minimize drag and stagnant flow regions within the flow cell. Similar to other flow cell designs, the height of the flow cell was controlled between 100 and $1000 \mu \mathrm{m}$ by the distance between two parallel plates. However, in this design, the top plate was deflected into the flow cell, as shown in Figure 20. The shape of the deflected channel profile was used to control the pressure drop of the fluid across the width of the flow channel, providing for a uniform flow front. Dye injection evaluations of flow fields within an $800 \mu \mathrm{m}$-high parallel plate and a deflected plate flow cell are shown in Figure 21. The parallel plate flow cell shows a distinctive parabolic flow profile, while the deflected plate profile shows a much more uniform flow front both at the inlet and middle of the flow cell. The flow cell was used to produce CdS films between 20 and $40 \mathrm{~nm}$ in thickness with variations down 
to $10 \%$ across a $150 \times 150-\mathrm{mm}$ glass substrate. The thickness of the film deposited was found to be between three and five times more uniform than films produced using the parallel-plate flow cell. This level of film uniformity compared favorably with prior continuous reactor flow cells for solution deposition, showing over fivefold more variation in chemical product (nanowire) dimensions over a 30-mm dimension [24].

Figure 20. (a) Top view of the MASD flow cell design and (b) the deflected channel profile from the equivalent channel heights. Reproduced from [49].
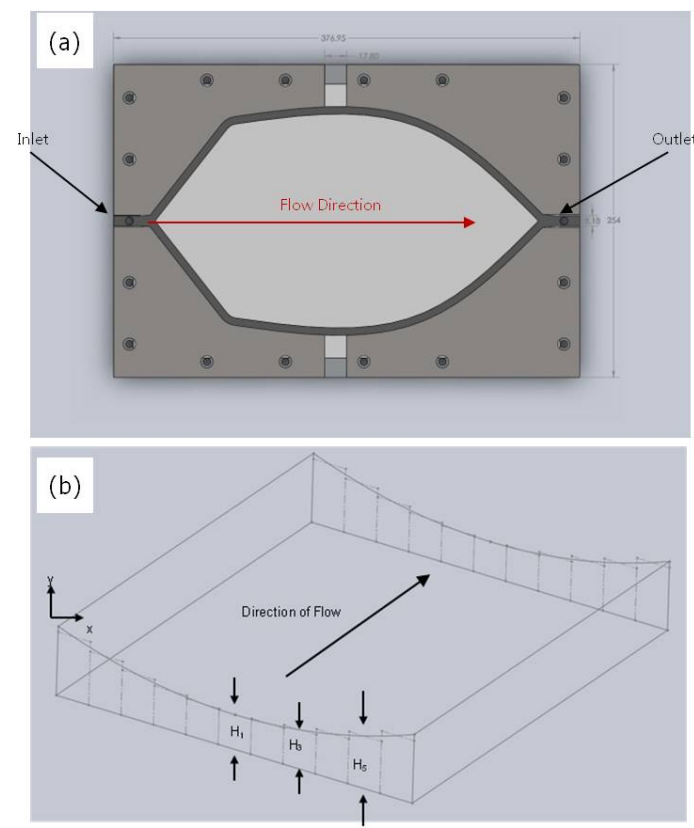

Figure 21. Flow distributions at the beginning (top) and middle (bottom) of the flow cell for the parallel plate (left) and the deflected plate (right) flow cells. Reproduced from [49].
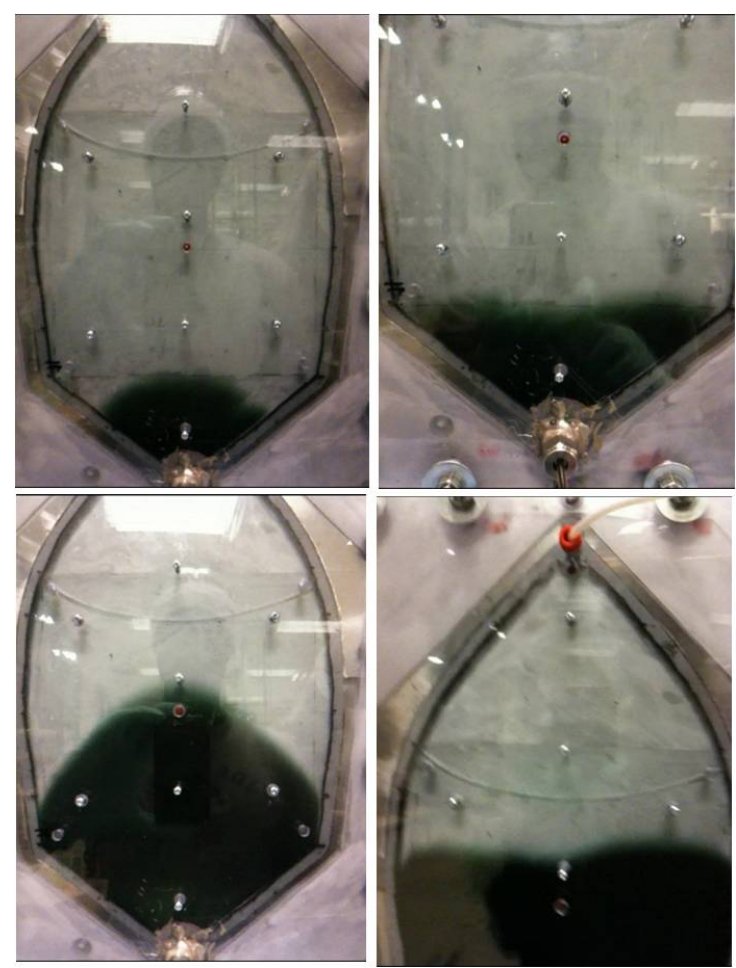


\section{Conclusions and Future Directions}

The microreactor-assisted solution deposition (MASD) process combines the benefits of microreaction technology and solution-based deposition processes for the fabrication of semiconductor thin films. MASD is a new approach that could be adopted for many chemical solution deposition processes to enable the low-temperature deposition of many compound semiconductor thin films for the manufacturing of functional devices. In particular, it is able to produce reactive fluxes of short-life, intermediate molecules to promote heterogeneous growth and alleviate the drawbacks of the conventional batch chemical solution deposition process. MASD provides opportunities to fabricate high quality compound semiconductor thin films using low-cost capital equipment along with the scalability for numbering-up the process towards an industrial production scale.

There are some challenges associated with MASD. One fundamental challenge is the depletion of reactants along with the residence time of the chemical solution. A beautiful example reported by McPeak et al. clearly illustrates this issue [62]. In their study, the deposition of ZnCdS thin films by CBD using a continuous flow microreactor was performed. As shown in Figure 22, over the length of a single substrate, films showed an increasing $\mathrm{Zn}$ :Cd ratio, a resultant monotonic increase in the band gap from 2.42 to $2.75 \mathrm{eV}$ and significant thickness variation.

Figure 22. (a) Plug flow reactor model showing the $\mathrm{Zn}$ and $\mathrm{Cd}$ bath concentration as a function of the position (thick lines), the laminar flow profile (thin line) and the temperature profile (color gradation indicates a change from 70 to $\sim 60{ }^{\circ} \mathrm{C}$ ) in the continuous flow microreactor; (b) $\mathrm{CdZnS}$ deposition on a Si wafer showing the interference pattern arising from the spatial variation in the film thickness; (c) The CdZnS film thickness as a function of the distance from the inlet. Reproduced from [62].

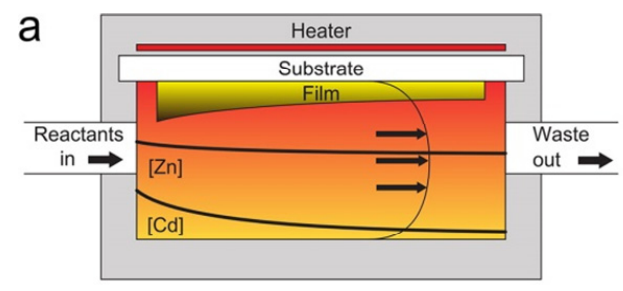

b
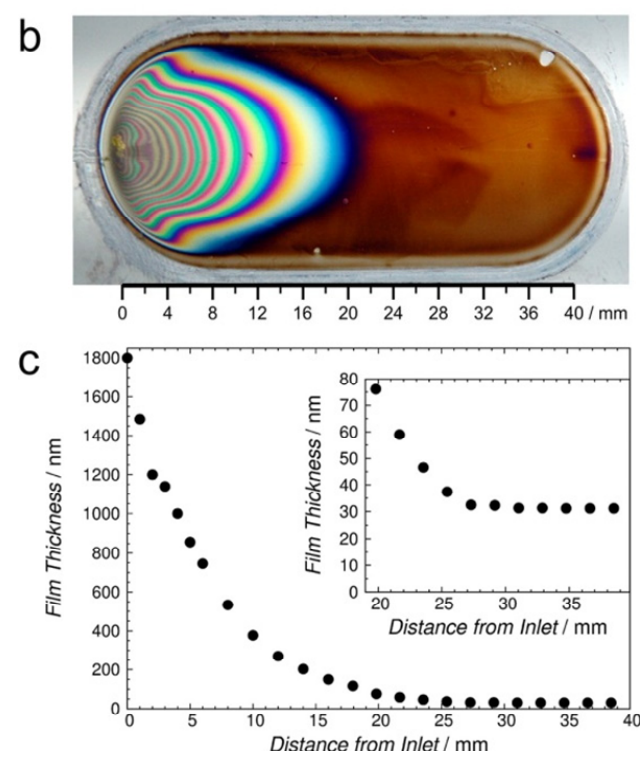
The MASD process opens up several opportunities that are difficult to achieve by the conventional chemical bath deposition process. The temporal control offered by MASD provides the capability to deposit tailored thin films, such as functional gradient thin films. Some examples of thin films with a compositional gradient and that are layer-by-layer are illustrated in Figure 23. The possibility of continuously generating reactive species by MASD should also expand the material spaces that were previously not covered by the conventional batch chemical bath deposition processes, due to the tendency of many reactive species towards particle formation instead of film formation. It will be exciting to see some examples demonstrating some of these capabilities by MASD in the near future.

Figure 23. Tailored thin films potentially fabricated by MAND: (a) three different layers on a substrate; and (b) compositional gradients.
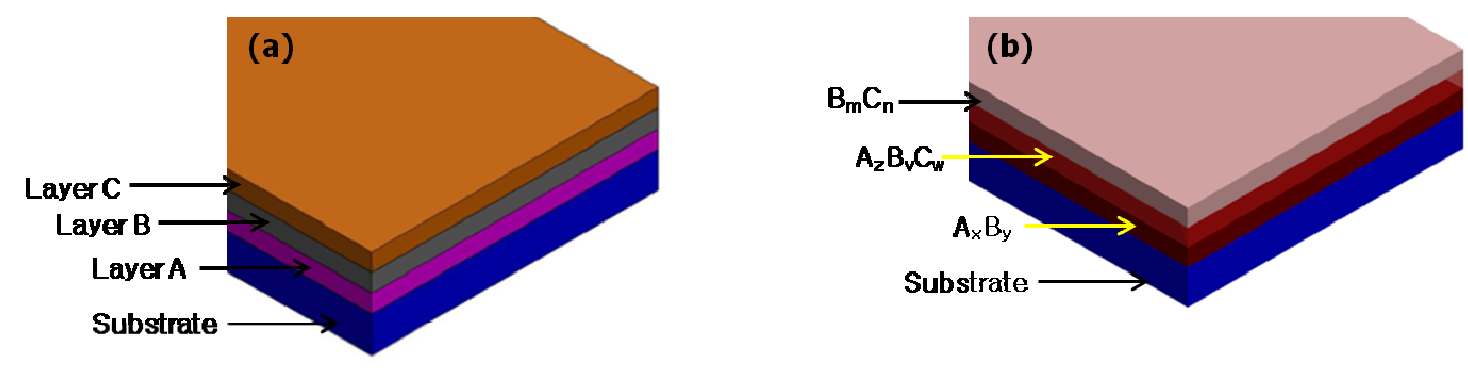

\section{Acknowledgments}

The authors are grateful for the fruitful collaboration with Curtis Voss, Yu-Jen Chang, Seung-yeol Han, Prakash Mugdur, Si Ok Ryu, Sudhir Ramprasad and Daniel Palo. The authors would like to acknowledge the financial support from the National Science Foundation CAREER CTS-0348723, CBET-0654434, the Department of Energy's Office of Energy Efficiency and Renewable Energy (EERE), the Industrial Technology Program (ITP), the Nanomanufacturing Activity through award number NT08847 DOE ITP, the Oregon Nanoscience and Microtechnology Institute (ONAMI) and Oregon Built Environment \& Sustainable Technologies (Oregon BEST).

\section{Conflicts of Interest}

The authors declare no conflict of interest.

\section{References}

1. Schlesinger, T.E. Electrodepostion of Semiconductors; John Wiley and Sons, Inc.: Hoboken, NJ, USA, 2000; Volume 14.

2. Mane, R.S.; Lokhande, C.D. Chemical deposition method for metal chalcogenide thin films. Mater. Chem. Phys. 2000, 65, 1-31.

3. Mwakikunga, B.W. Progress in ultrasonic spray pyrolysis for condensed matter sciences developed from ultrasonic nebulization theories since michael faraday. Crit. Rev. Solid State Mater. Sci. 2014, 39, 46-80.

4. Hodes, G. Chemical Solution Deposition of Semiconductor Films; Marcel Dekker: New York, NY, USA, 2003. 
5. Ortegaborges, R.; Lincot, D. Mechanism of chemical bath deposition of cadmium-sulfide thin-films in the ammonia-thiourea system-In-situ kinetic-study and modelization. J. Electrochem. Soc. 1993, 140, 3464-3473.

6. Chang, Y.J.; Su, Y.W.; Lee, D.H.; Ryu, S.O.; Chang, C.H. Investigate the reacting flux of chemical bath deposition by a continuous flow microreactor. Electrochem. Solid State Lett. 2009, 12, $\mathrm{H} 244-\mathrm{H} 247$.

7. Han, S.Y.; Chang, Y.J.; Lee, D.H.; Ryu, S.O.; Lee, T.J.; Chang, C.H. Chemical nanoparticle deposition of transparent zno thin films. Electrochem. Solid State Lett. 2007, 10, K1-K5.

8. Liu, S.; Chang, C.-H.; Paul, B.K.; Remcho, V.T. Convergent synthesis of polyamide dendrimer using a continuous flow microreactor. Chem. Eng. J. 2008, 135, S333-S337.

9. Ramprasad, S.; Su, Y.-W.; Chang, C.-H.; Paul, B.K.; Palo, D.R. Cadmium sulfide thin film deposition: A parametric study using microreactor-assisted chemical solution deposition. Sol. Energy Mater. Sol. Cells 2012, 96, 77-85.

10. Reynolds, J.E. On the synthesis of galena by means of thiocarbamide, and the deposition of lead sulphide as a specular film. J. Chem. Soc. 1884, 45, 162-165.

11. Voss, C.; Chang, Y.J.; Subramanian, S.; Ryu, S.O.; Lee, T.J.; Chang, C.H. Growth kinetics of thin-film cadmium sulfide by ammonia-thiourea based CBD. J. Electrochem. Soc. 2004, 151, C655-C660.

12. Chang, Y.J.; Mugdur, P.H.; Han, S.Y.; Morrone, A.A.; Ryu, S.O.; Lee, T.J.; Chang, C.H. Nanocrystalline CdS MISFETs fabricated by a novel continuous flow microreactor. Electrochem. Solid State Lett. 2006, 9, G174-G177.

13. Lee, D.H.; Jung, J.Y.; Bae, E.J.; Lee, T.J.; Ryu, S.O.; Chang, C.H. Highly uniform ZnS thin film through the continuous flow reaction process. J. Korean Phys. Soc. 2008, 53, 102-105.

14. Lee, J.Y.; Park, M.S.; Lee, T.J.; Ryu, S.O.; Chang, C.H.; Ryu, S.O. Synthesis of CdTe thin films for solar cell using solution-based deposition methods at low temperature. Mol. Cryst. Liq. Cryst. 2011, 551, 181-190.

15. Kim, C.R.; Han, S.Y.; Chang, C.H.; Lee, T.J.; Ryu, S.O. A study on copper selenide thin films for photovoltaics by a continuous flow microreactor. Mol. Cryst. Liq. Cryst. 2010, 532, 455-463.

16. Park, M.S.; Han, S.Y.; Bae, E.J.; Lee, T.J.; Chang, C.H.; Ryu, S.O. Synthesis and characterization of polycrystalline $\mathrm{CuInS}_{2}$ thin films for solar cell devices at low temperature processing conditions. Curr. Appl. Phys. 2010, 10, S379-S382.

17. Kim, C.R.; Han, S.Y.; Chang, C.H.; Lee, T.J.; Ryu, S.O. Synthesis and characterization of $\mathrm{CuInSe}_{2}$ thin films for photovoltaic cells by a solution-based deposition method. Curr. Appl. Phys. 2010, 10, S383-S386.

18. Yamamoto, Y.; Yamaguchi, T.; Tanaka, T.; Tanahashi, N.; Yoshida, A. Characterization of $\mathrm{CuInS}_{2}$ thin films prepared by sputtering from binary compounds. Sol. Energy Mater. Sol. Cells 1997, 49, 399-405.

19. Peng, S.; Cheng, F.; Liang, J.; Tao, Z.; Chen, J. Facile solution-controlled growth of $\mathrm{CuInS}_{2}$ thin films on $\mathrm{FTO}$ and $\mathrm{TiO}_{2} / \mathrm{FTO}$ glass substrates for photovoltaic application. J. Alloys Compd. 2009, $481,786-791$. 
20. Peza-Tapia, J.M.; Sanchez-Resendiz, V.M.; Albor-Aguilera, M.L.; Cayente-Romero, J.J.; de Leon-Gutierrez, L.R.; Ortega-Lopez, M. Electrical and optical characterization of Na: $\mathrm{CuInS}_{2}$ thin films grown by spray pyrolysis. Thin Solid Films 2005, 490, 142-145.

21. Ozgur, U.; Alivov, Y.I.; Liu, C.; Teke, A.; Reshchikov, M.A.; Dogan, S.; Avrutin, V.; Cho, S.J.; Morkoc, H. A comprehensive review of $\mathrm{ZnO}$ materials and devices. J. Appl. Phys. 2005, 98, doi:10.1063/1.1992666.

22. Tian, Z.R.R.; Voigt, J.A.; Liu, J.; McKenzie, B.; McDermott, M.J.; Rodriguez, M.A.; Konishi, H.; $\mathrm{Xu}$, H.F. Complex and oriented $\mathrm{ZnO}$ nanostructures. Nat. Mater. 2003, 2, 821-826.

23. Wang, X.; Liao, M.; Zhong, Y.; Zheng, J.Y.; Tian, W.; Zhai, T.; Zhi, C.; Ma, Y.; Yao, J.; Bando, Y.; et al. ZnO hollow spheres with double-yolk egg structure for high-performance photocatalysts and photodetectors. Adv. Mater. 2012, 24, 3421-3425.

24. McPeak, K.M.; Baxter, J.B. ZnO nanowires grown by chemical bath deposition in a continuous flow microreactor. Cryst. Growth Des. 2009, 9, 4538-4545.

25. Han, S.-Y.; Paul, B.K.; Chang, C.-H. Nanostructured $\mathrm{ZnO}$ as biomimetic anti-reflective coatings on textured silicon using a continuous solution process. J. Mater. Chem. 2012, 22, 22906-22912.

26. Nair, P.K.; Campos, J.; Nair, M.T.S. Opto-electronic characteristics of chemically deposited cadmium sulphide thin films. Semicond. Sci. Technol. 1988, 3, doi:10.1088/0268-1242/3/2/010.

27. Arreola-Jardon, G.; Gonzalez, L.A.; Garcia-Cerda, L.A.; Gnade, B.; Quevedo-Lopez, M.A.; Ramirez-Bon, R. Ammonia-free chemically deposited CdS films as active layers in thin film transistors. Thin Solid Films 2010, 519, 517-520.

28. Birkmire, R.W.; McCandless, B.E. Cdte thin film technology: Leading thin film PV into the future. Curr. Opin. Solid State Mater. Sci. 2010, 14, 139-142.

29. Mugdur, P.H.; Chang, Y.J.; Han, S.Y.; Su, Y.W.; Morrone, A.A.; Ryu, S.O.; Lee, T.J.; Chang, C.H. A comparison of chemical bath deposition of $\mathrm{CdS}$ from a batch reactor and a continuous-flow microreactor. J. Electrochem. Soc. 2007, 154, D482-D488.

30. Dona, J.M.; Herrero, J. Chemical bath deposition of CdS thin-films-Electrochemical in situ kinetic-studies. J. Electrochem. Soc. 1992, 139, 2810-2814.

31. Chang, Y.J.; Munsee, C.L.; Herman, G.S.; Wager, J.F.; Mugdur, P.; Lee, D.H.; Chang, C.H. Growth, characterization and application of US thin films deposited by chemical bath deposition. Surface Interface Anal. 2005, 37, 398-405.

32. Nair, P.K.; Garcia, V.M.; Gomez-Daza, O.; Nair, M.T.S. High thin-film yield achieved at small substrate separation in chemical bath deposition of semiconductor thin films. Semicond. Sci. Technol. 2001, 16, 855-863.

33. Boyle, D.S.; Bayer, A.; Heinrich, M.R.; Robbe, O.; O’Brien, P. Novel approach to the chemical bath deposition of chalcogenide semiconductors. Thin Solid Films 2000, 361, 150-154.

34. Lerou, J.J.; Harold, J.; Ryley, J.; Ashmead, J.; O’Brien, T.C.; Johnson, M.; Perrotto, J.; Blaisdell, C.T.; Rensi, T.A.; Nyquist, J. Microfabricated mini-chemical systems: Technical feasibility. In Microsystem Technology for Chemical and Biological Microreactors, Dechema Monographs; Ehrfeld, W., Ed.; Verlag Chemie: Weinheim, Germany, 1996; Volume 132, pp. 51-69.

35. Chang, C.-H.; Paul, B.K.; Remcho, V.T.; Atre, S.; Hutchison, J.E. Synthesis and post-processing of nanomaterials using microreaction technology. J. Nanopart. Res. 2008, 10, 965-980. 
36. Schenk, R.; Hessel, V.; Hofmann, C.; Lowe, H.; Schonfeld, F. Novel liquid-flow splitting unit numbering-up of liquid/liquid specifically made for chemical microprocessing. Chem. Eng. Technol. 2003, 26, 1271-1280.

37. Saber, M.; Commenge, J.M.; Falk, L. Microreactor numbering-up in multi-scale networks for industrial-scale applications: Impact of flow maldistribution on the reactor performances. Chem. Eng. Sci. 2010, 65, 372-379.

38. Tonomura, O.; Tominari, T.; Kano, M.; Hasebe, S. Operation policy for micro chemical plants with external numbering-up structure. Chem.Eng. J. 2008, 135, S131-S137.

39. Schenk, R.; Hessel, V.; Hofmann, C.; Kiss, J.; Lowe, H.; Ziogas, A. Numbering-up of micro devices: A first liquid-flow splitting unit. Chem. Eng. J. 2004, 101, 421-429.

40. Kashid, M.N.; Gupta, A.; Renken, A.; Kiwi-Minsker, L. Numbering-up and mass transfer studies of liquid-liquid two-phase microstructured reactors. Chem. Eng. J. 2010, 158, 233-240.

41. Iwasaki, T.; Kawano, N.; Yoshida, J.-I. Radical polymerization using microflow system: Numbering-up of microreactors and continuous operation. Org. Process. Res. Dev. 2006, 10, 1126-1131.

42. Deshmukh, S.R.; Tonkovich, A.L.Y.; Jarosch, K.T.; Schrader, L.; Fitzgerald, S.P.; Kilanowski, D.R.; Lerou, J.J.; Mazanec, T.J. Scale-up of microchannel reactors for fischer-tropsch synthesis. Ind. Eng. Chem. Res. 2010, 49, 10883-10888.

43. Mae, K.; Maki, T.; Hasegawa, I.; Eto, U.; Mizutani, Y.; Honda, N. Development of a new micromixer based on split/recombination for mass production and its application to soap free emulsifier. Chem. Eng. J. 2004, 101, 31-38.

44. Kockmann, N.; Gottsponer, M.; Roberge, D.M. Scale-up concept of single-channel microreactors from process development to industrial production. Chem. Eng. J. 2011, 167, 718-726.

45. Bally, F.; Serra, C.A.; Hessel, V.; Hadziioannou, G. Micromixer-assisted polymerization processes. Chem. Eng. Sci. 2011, 66, 1449-1462.

46. Pysall, D.; Wachsen, O.; Bayer, T.; Wulf, S. Method and Device for Continuous Production of Polymers. U.S. Patent 20140011914, 9 January 2014.

47. Wirth, T. Microreactors in Organic Synthesis and Catalysis; Wiley-VCH: Weinheim, Germany, 2008.

48. Fox, M.B.; Esveld, D.C.; Boom, R.M. Conceptual design of a mass parallelized PEF microreactor. Trends Food Sci. Technol. 2007, 18, 484-491.

49. Paul, B.K.; Hires, C.L.; Su, Y.W.; Chang, C.H.; Rarnprasad, S.; Palo, D. A uniform residence time flow cell for the microreactor-assisted solution deposition of CdS on an FTO-glass substrate. Cryst. Growth Des. 2012, 12, 5320-5328.

50. Ramprasad, S.; Su, Y.-W.; Chang, C.-H.; Paul, B.K.; Palo, D.R. Continuous microreactor-assisted solution deposition for scalable production of CdS films. Ecs J. Solid State Sci. Technol. 2013, 2 , P333-P337.

51. Benson, R.S.; Ponton, J.W. Process miniaturization-A route to total environmental acceptability. Chem. Eng. Res. Des. 1993, 71, 160-168.

52. Bokenkamp, D.; Desai, A.; Yang, X.; Tai, Y.C.; Marzluff, E.M.; Mayo, S.L. Microfabricated silicon mixers for submillisecond quench-flow analysis. Anal. Chem. 1998, 70, 232-236.

53. Nguyen, N.T.; Wu, Z.G. Micromixers-A review. J. Micromech. Microeng. 2005, 15, R1-R16. 
54. Löwe, H.; Ehrfeld, W.; Hessel, V.; Richter, T.; Schiewe, J. Micromixing Technology. In Proceedings of the 4th International Conference on Microreaction Technology (IMRET), Atlanta, GA, USA, 5-9 March 2000; pp. 31-47.

55. Peterson, D.A.; Chandran, P.; Paul, B.K. A reverse oscillatory flow microreactor system for the synthesis of uniformly-size $\mathrm{CdS}$ nanoparticles. In Proceedings of the IEEE International Conference on Nanotechnology, Portland, OR, USA, 15-18 August 2011; pp. 666-670.

56. Sugano, K.; Yoshimune, H.; Nakata, A.; Hirai, Y.; Tsuchiya, T.; Tabata, O. High-speed pulsed mixing with high-frequency switching of micropump driving and its application to nanoparticle synthesis. In Proceedings of the 16th International Solid-State Sensors, Actuators and Microsystems Conference (Transducers), Beijing, China, 5-9 June 2011; pp. 1773-1776.

57. Jin, H.D.; Garrison, A.; Tseng, T.; Paul, B.K.; Chang, C.-H. High-rate synthesis of phosphine-stabilized undecagold nanoclusters using a multilayered micromixer. Nanotechnology 2010, 21, doi:10.1088/0957-4484/21/44/445604.

58. Chung, B.J.; Robertson, A.M.; Peters, D.G. The numerical design of a parallel plate flow chamber for investigation of endothelial cell response to shear stress. Comput. Struct. 2003, 81, 535-546.

59. Hung, P.J.; Lee, P.J.; Sabounchi, P.; Aghdam, N.; Lin, R.; Lee, L.P. A novel high aspect ratio microfluidic design to provide a stable and uniform microenvironment for cell growth in a high throughput mammalian cell culture array. Lab. Chip 2005, 5, 44-48.

60. Jones, B.J.; Lee, P.-S.; Garimella, S.V. Infrared micro-particle image velocimetry measurements and predictions of flow distribution in a microchannel heat sink. Int. J. Heat Mass Transf. 2008, $51,1877-1887$.

61. Pan, M.; Tang, Y.; Pan, L.; Lu, L. Optimal design of complex manifold geometries for uniform flow distribution between microchannels. Chem. Eng. J. 2008, 137, 339-346.

62. McPeak, K.M.; Opasanont, B.; Shibata, T.; Ko, D.-K.; Becker, M.A.; Chattopadhyay, S.; Bui, H.P.; Beebe, T.P., Jr.; Bunker, B.A.; Murray, C.B.; et al. Microreactor chemical bath deposition of laterally graded $\mathrm{Cd}_{1-x} \mathrm{Zn}_{x} \mathrm{~S}$ thin films: A route to high-throughput optimization for photovoltaic buffer layers. Chem. Mater. 2013, 25, 297-306.

(C) 2014 by the authors; licensee MDPI, Basel, Switzerland. This article is an open access article distributed under the terms and conditions of the Creative Commons Attribution license (http://creativecommons.org/licenses/by/3.0/). 